\title{
Hydrothermal fluid geochemistry at the Iheya North field in the mid-Okinawa Trough: Implication for origin of methane in subseafloor fluid circulation systems
}

\author{
Shinsuke KAWAGUCCI, ${ }^{1,2 *}$, Hitoshi ChiBA,${ }^{3}$ JUn-ICHIRo IshiBASHI, ${ }^{4}$ TOSHIRO YAMANAKA,${ }^{3}$ TOMOHIRO TOKI,${ }^{5}$ \\ Yasuyuki Muramatsu, ${ }^{6}$ Yuichiro Ueno,,${ }^{2,7}$ Akiko Makabe, ${ }^{8}$ KaZuhiro Inoue,${ }^{8}$ NaOhiro Yoshida, ${ }^{8}$

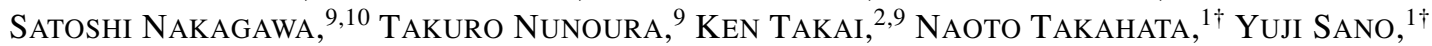 \\ TAKU NARITA, ${ }^{1}$ Genta Teranishi, ${ }^{1}$ HaJime OBATA ${ }^{1 \dagger}$ and TOSHITAKA GAMO ${ }^{1 \dagger}$ \\ ${ }^{1}$ Ocean Research Institute (ORI), The University of Tokyo, 1-15-1, Minamidai, Nakano-ku, Tokyo 164-8639, Japan \\ ${ }^{2}$ Precambrian Ecosystem Laboratory (PEL), Japan Agency for Marine-Earth Science and Technology (JAMSTEC), \\ 2-15 Natsushima-cho, Yokosuka 237-0061, Japan \\ ${ }^{3}$ Department of Earth Science, Graduate School of Natural Science and Technology, Okayama University, \\ 3-1-1 Tsushima-naka, Kita, Okayama, Okayama 700-8530, Japan \\ ${ }^{4}$ Faculty of Sciences, Kyushu University, 6-10-1, Hakozaki, Higashi, Fukuoka 812-8581, Japan \\ ${ }^{5}$ Faculty of Science, University of the Ryukyus, 1 Senbaru, Nishihara, Okinawa 903-0213, Japan \\ ${ }^{6}$ Faculty of Science, Gakushuin University, Nejiro 1-5-1, Toshima-ku, Tokyo 171-8588, Japan \\ ${ }^{7}$ Global Edge Institute, Tokyo Institute of Technology, G1-25, Nagatsuta, Midori-ku, Yokohama 226-8502, Japan \\ ${ }^{8}$ Department of Environmental Science and Technology, Tokyo Institute of Technology, \\ G1-25, Nagatsuta, Midori-ku, Yokohama 226-8502, Japan \\ ${ }^{9}$ Subsurface Geobiology Advanced Research (SUGAR) Project, Japan Agency for Marine-Earth Science and Technology (JAMSTEC), \\ 2-15 Natsushima-cho, Yokosuka 237-0061, Japan \\ ${ }^{10}$ Faculty of Fisheries Sciences, Hokkaido University, 3-1-1 Minato-cho, Hakodate 041-8611, Japan
}

(Received March 3, 2010; Accepted August 16, 2010)

\begin{abstract}
Geochemical characteristics of hydrothermal fluids in the Iheya North hydrothermal field, mid-Okinawa Trough, was investigated. Twelve-years observation reveals temporal variation of vent fluid chemistry potentially controlled by temporally varying pattern of the phase-separation and -segregation, while the constant Element/Cl ratios among the periods and chimneys indicate the stable chemical composition of the source hydrothermal fluid prior to undergoing phaseseparation. The high $\mathrm{K}$ contents in the estimated source fluid are typical in the arc-backarc hydrothermal systems due to the hydrothermal reaction with the K-enriched felsic rocks. The high I, B and $\mathrm{NH}_{4}$ contents and alkalinity are derived from decomposition of the sedimentary organic matters.

Compositional and isotopic properties of gas species, $\mathrm{CH}_{4}, \mathrm{H}_{2}, \mathrm{CO}_{2}$, and $\mathrm{C}_{2} \mathrm{H}_{6}$, strongly suggest a dominance of biogenic $\mathrm{CH}_{4}$ associated with the sedimentary organic matter. Based on the carbon mass balance calculation and the multidisciplinary investigations of the Iheya North hydrothermal system since the discovery, we hypothesized that the microbial methanogenesis occurs not only within the Central Valley where hydrothermal vents exist, but also in the spatially abundant and widespread basin-filling sediments surrounding the Iheya North Knoll, and that the microbially produced $\mathrm{CH}_{4}$ is recharged together with the source fluid into the deep hydrothermal reaction zone. This "Microbial Methanogenesis at Recharge area in hydrothermal circulation" (MMR) model would be an implication for the generation and incorporation of hydrothermal fluid $\mathrm{CH}_{4}$ in the deep-sea hydrothermal systems but also for those of cold seep $\mathrm{CH}_{4}$ and for the presently uncertain hydrothermal fluid paths in the subseafloor environments. In the near future, the IODP drilling will be conducted in the Iheya North hydrothermal system, and give an excellent opportunity to testify our MMR model.
\end{abstract}

Keywords: origin of methane, sediment-associated hydrothermal field, Iheya North hydrothermal field, Okinawa Trough, hydrothermal fluid geochemistry

*Corresponding author (e-mail: kawagucci@jamstec.go.jp)

${ }^{\dagger}$ Present address: Atmosphere and Ocean Research Institute, The University of Tokyo, 5-1-5, Kashiwanoha, Kashiwa, Chiba 277-8564, Japan.

Copyright $@ 2011$ by The Geochemical Society of Japan.

\section{INTRODUCTION}

Hydrothermal fluid chemistry in the Okinawa Trough hydrothermal systems has been often characterized by higher concentrations of $\mathrm{CO}_{2}, \mathrm{CH}_{4}, \mathrm{NH}_{4}, \mathrm{I}$ and $\mathrm{K}$ and higher alkalinity than those in typical sediments-free Mid 


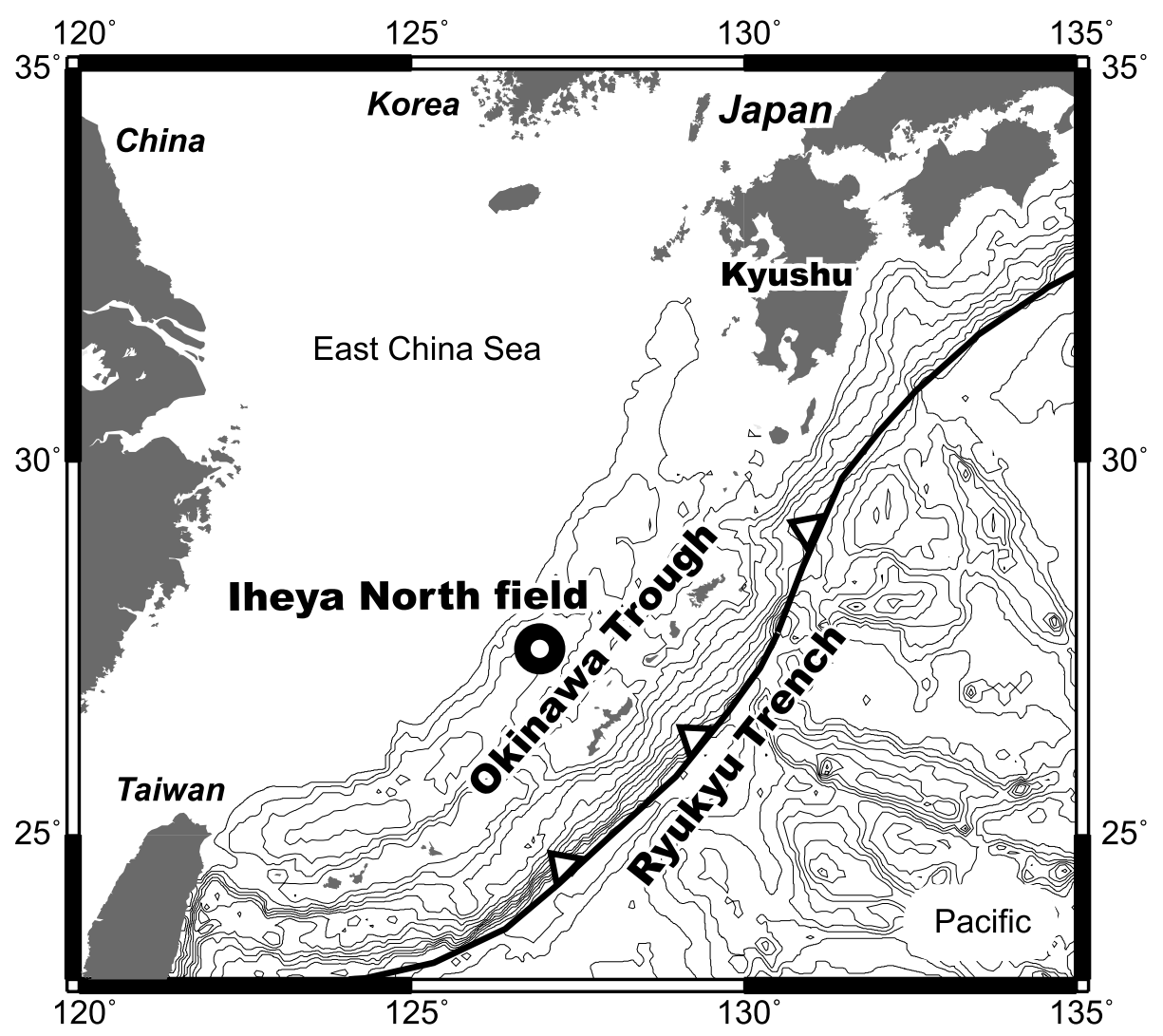

Fig. 1. Map of the Okinawa Trough with the location of the Iheya North hydrothermal field.

Ocean Ridge (MOR) hydrothermal fluids (Sakai et al., 1990a, b; Gamo et al., 1991; Chiba et al., 1993; Nakano et al., 2001; Kishida et al., 2004; Konno et al., 2006; Inagaki et al., 2006; Hongo et al., 2007; Suzuki et al., 2008). The notable hydrothermal fluid chemistry has been linked with the tectonic settings and the existing thick terrigenous sediments of the Okinawa Trough. Philippine plate subduction along the Ryukyu trench-arc system provides $\mathrm{K}$-enriched and volatiles-rich dacitic-rhyolitic magma supply in the Okinawa Trough (e.g., Sakai et al., 1990a; Gamo et al., 2006). Organics-rich terrigenous sediments burying the Okinawa Trough (Narita et al., 1990) not only supply the sedimentary chemical inputs ( $\mathrm{NH}_{4}$, I, etc.) (Gamo et al., 1991; You et al., 1994) but also promote the widespread occurrence of functionally active microbial communities and the microbiological impacts on the hydrothermal fluid circulation (Inagaki et al., 2006; Nunoura et al., 2010). In addition to the chemical aspects potentially affecting the hydrothermal fluid chemistry, relatively shallow water depths of many Okinawa Trough hydrothermal systems serve as a physical factor to induce frequent boiling (subcritical phaseseparation) and subsequent phase-segregation, because the boiling temperature of seawater steeply decreases with decreasing pressure at around 100 bar (Bischoff and Rosenbauer, 1988). The phase-separation and -segregation sometimes results in quite different chemical compositions of the hydrothermal fluids among different vent sites in the same hydrothermal field although they are derived from the common source fluid (Gamo, 1995).

As one of the most fundamental questions to the Okinawa Trough hydrothermal fluids, it has been discussed how and where the abundant $\mathrm{CH}_{4}$ is generated and supplied into the hydrothermal fluids (Chiba et al., 1993; Ishibashi et al., 1995; Konno et al., 2006). At hydrothermal systems, there are a variety of possible contributors to the $\mathrm{CH}_{4}$, including chemical synthesis from reduction of $\mathrm{CO}_{2}$ during hydrothermal circulation (e.g., McCollom and Seewald, 2007), thermal decomposition of organic matter (e.g., Giggenbach, 1997), and microbial hydrogenotrophic and fermentative methanogenesis (e.g., Valentine et al., 2004b). In the early study of the Okinawa Trough hydrothermal fluids in the JADE field of the Izena Cauldron, it was suggested that the abundant $\mathrm{CH}_{4}$ should be produced by thermal decomposition of sedimentary organic matters during high temperatures of fluid circulation (Ishibashi et al., 1995). However, recent investigations have demonstrated the compositional and isotopic 


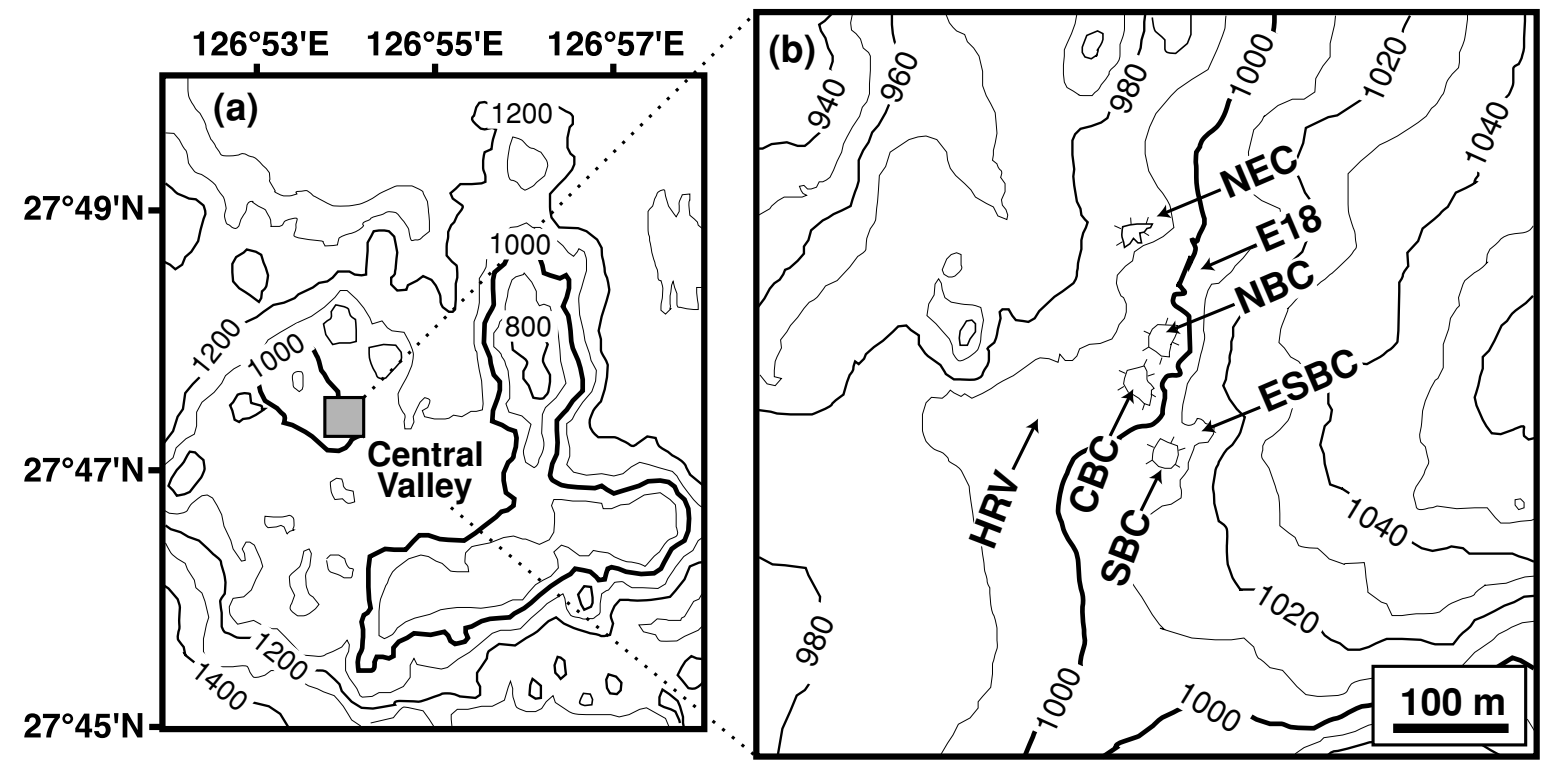

Fig. 2. Locations of the Iheya North field ( $a$ ) and each vent site (b).

variation of hydrothermal fluid $\mathrm{CH}_{4}$ among the Okinawa Trough hydrothermal fields (e.g., concentrations and $\delta^{13} \mathrm{C}$ values of $\mathrm{CH}_{4}$ are respectively $7.6 \mathrm{mM}$ and $-41 \sim-36 \%$ o in the JADE field and 1.2 9.3 $\mathrm{mM}$ and $-27 \sim-24 \%$, in the Yonaguni Knoll IV filed) (Ishibashi et al., 1995; Konno et al., 2006). These results, especially the $\delta^{13} \mathrm{C}$ values, suggest that the generation and incorporation of $\mathrm{CH}_{4}$ in the hydrothermal fluids could differ among each hydrothermal field in the Okinawa Trough. In addition to the conventional thermogenic origin of $\mathrm{CH}_{4}$, microbial methanogenesis is now recognized to be operative in the elevated temperature range of the hydrothermally active subseafloor environments $\left(\leq 122^{\circ} \mathrm{C}\right)$ (Parkes et al., 2007; Takai et al., 2008a). Indeed, it has been pointed out that the microbial methanogenesis serves as a source of abundant $\mathrm{CH}_{4}$ in the hydrothermal fluids of other sedimentscovered hydrothermal systems (Pearson et al., 2005; Cruse and Seewald, 2006).

In this study, the compositional and isotopic characteristics of hydrothermal fluids in the Iheya North hydrothermal field, mid-Okinawa Trough, was investigated. Twelve-years observation revealed temporal variation of vent fluid chemistry potentially controlled by temporally varying pattern of the phase-separation and -segregation. In 2007, the detail gas chemistry was also characterized to clarify the generation and incorporation processes of hydrothermal fluid $\mathrm{CH}_{4}$ in the Iheya North field. Based on the results in this study and other geophysical and microbiological investigations of the Iheya North hydrothermal system, we hypothesize a model for generation and incorporation of abundant $\mathrm{CH}_{4}$ in the Okinawa Trough hydrothermal systems including the Iheya North field.

\section{OBSERVATION}

Geography and geology

A hydrothermal activity was discovered in 1995 by a deep-sea camera survey (Momma et al., 1996) in the Iheya North Knoll $\left(27^{\circ} 47^{\prime} 50 \mathrm{~N}, 126^{\circ} 53^{\prime} 80 \mathrm{E}\right)$, which was located about $150 \mathrm{~km} \mathrm{NNW}$ of the Okinawa Island (Fig. 1). Since the discovery, more than 40 dives by DSVs and ROVs have been conducted, and detail location of the hydrothermal activities and events at the seafloor has been well characterized. In the middle of the Iheya North Knoll, there is a valley, called as the "Central Valley" (Fig. 2a), representing the subseafloor structure with the relatively strong subbottom seismic reflectors (up to $300 \mathrm{~m}$ below seafloor surface). Based on the geophysical investigation and seafloor observation, it is now interpreted that the Central Valley is buried with abundant volcanic flow deposits of the pumicious rocks interbedded with layered minor sediments. However, the seafloor surface around the Iheya North hydrothermal field and the Central Valley are covered with the pelagic sediments. It is also notable that several faults with a north-south (N-S) trend are observed around the hydrothermal vent sites. Indeed, major hydrothermal vent chimneys (mounds) stand along one of the N-S faults (Fig. 2b).

The Iheya North hydrothermal field is located in the western cove of the Central Valley of the Iheya North Knoll (Fig. 2a). Totally, nine hydrothermal vent sites accompanying the proximal mounds named as North Edge Chimney (NEC), Event 18 (E18), North Big Chimney (NBC), Central Big Chimney (CBC), High Radioactivity Vent (HRV), Ese South Big Chimney (ESBC), 


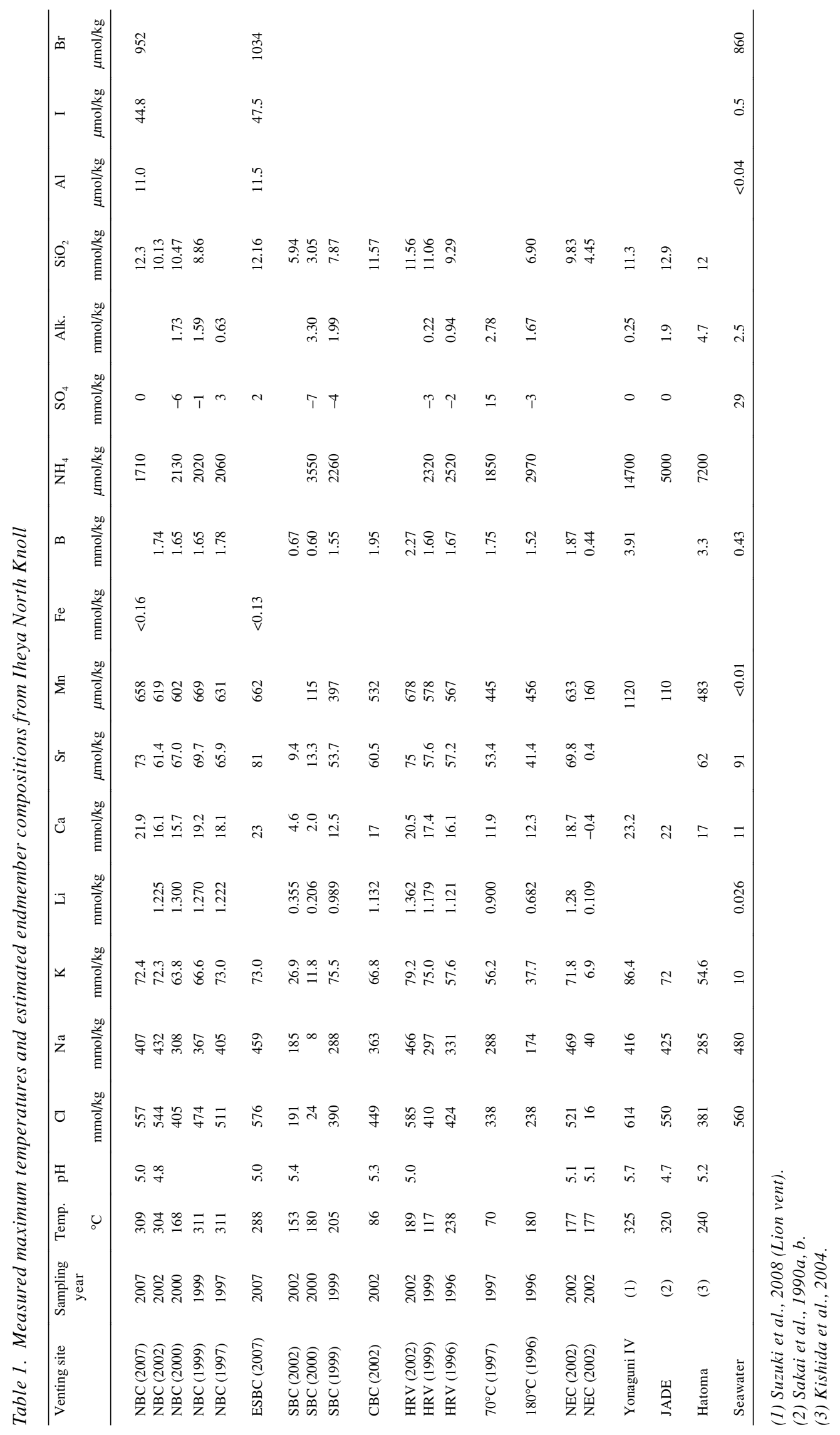


South Big Chimney (SBC), " $180^{\circ} \mathrm{C}$ vent" $(\sim 100 \mathrm{~m}$ south from SBC), and " $70^{\circ} \mathrm{C}$ vent" ( $100 \mathrm{~m}$ south from ESBC) from north to south are recognized (Fig. 2b). Among these mounds, a hydrothermal vent at NBC has had the highest temperature (maximum measured temperature of $311^{\circ} \mathrm{C}$, near the boiling point $\left(315^{\circ} \mathrm{C}\right.$ : Bischoff and Rosenbauer, $1988)$ at seafloor pressure (100 bar)) and the highest flowrate of hydrothermal emission $(\sim 1 \mathrm{~m} / \mathrm{sec}$ estimated based on video image observation) for more than 10 years, indicating that the NBC stands on the main hydrothermal flow or passage. The eight mounds of the nine (except for the HRV) are aligned in the N-S direction with the $\mathrm{NBC}$ at the center (Fig. 2b). With increasing distance from the NBC, the hydrothermal mounds have lower temperatures and lower flow-rates of hydrothermal emissions. The present hydrothermal vents and the diffusing flows are observed within $400 \mathrm{~m}$ in the N-S direction and $500 \mathrm{~m}$ in the east-west (E-W) direction. The west side of the hydrothermal field is the pumicious volcanic rock and the southern or eastern side is covered with the sediments.

The sedimentation in the Iheya North Knoll and the surrounding basin is a key for hydrothermal fluid chemistry of the Iheya North field. The sediments in the midOkinawa Trough are primarily supplied laterally from the East China Sea, largely originated from the Yangtze River (Narita et al., 1990). The sedimentation rate is still controversial in different area of the Okinawa Trough but is estimated to be $1-2 \mathrm{~m} \mathrm{ka}^{-1}$ in the mid Okinawa Trough (Tsugaru et al., 1991). The sediment cores obtained from the basin around the Iheya North Knoll during JAMSTEC KR01-09 cruise were frequently intervened by pumice layers and showed an average organic carbon content of the subseafloor sediments (>1 mbsf) at $0.001 \%(\mathrm{w} / \mathrm{w})$.

\section{Sampling and sample treatment}

The first sampling of the hydrothermal fluid was carried out by DSV "Shinkai 2000" in 1996. Then, the fluid samples have been collected from various hydrothermal chimney sites by Shinkai 2000 and ROV "Hyper Dolphin" (Table 1). The fluid sampling was conducted by using ORI-pump sampler (Sakai et al., 1990b), plastic bags with peristaltic pump, and a gas-tight sampler WHATS II (Saegusa et al., 2006). The temperature of each vent fluid was monitored during the sampling using a Pt resistant temperature probe equipped at the intake of sampling systems. The fluid samples were filtered by 0.2 or 0.45 $\mu \mathrm{m}$ pore-size filters in order to remove particles prior to subsumpling for each of the chemical analyses. The samples for onshore cation analyses were acidified by nitric or hydrochloric acids down to at $\mathrm{pH}<2$.

In 2007, we obtained the fluid samples for gas analyses by WHATS II. After the recovery of WHATS II onboard, the fluids in stainless-steel gas-tight bottles (150 $\mathrm{mL}$ ) were immediately opened to a vacuum line ( $c a .1500$
$\mathrm{mL}$ ) to recover the gas components. Reagent-grade solid sulfamic acid $\left(\mathrm{HOSO}_{2} \mathrm{NH}_{2}\right)$ was added to the fluid in the vacuum line to extract $\mathrm{CO}_{2}$. After degassing for $10 \mathrm{~min}$, the gas phase was collected into $50 \mathrm{~mL}$ stainless bottles for the subsequent gas analyses. At the same time, all of the degassed liquid phase was filtered (using a $0.45 \mu \mathrm{m}$ pore-size filter) and collected for the magnesium measurements. In addition to the gas chemistry analyses of natural fluid samples, an onboard incubation experient was carried out to assess the microbial $\mathrm{H}_{2}$ consumption in the diffusing hydrothermal fluid in terms of the compositional and isotopic composition of $\mathrm{H}_{2}$. The diffusing fluid was taken from a dense Paralvinella colony at NBC into three bottles by WHATS II, then the bottles were incubated onboard under room temperature $\left(25^{\circ} \mathrm{C}\right)$ (Table 2).

\section{Analyses}

The major cation concentrations $(\mathrm{Mg}, \mathrm{Na}, \mathrm{K}, \mathrm{Li}, \mathrm{Ca}$, $\mathrm{Sr}, \mathrm{Fe}$, and $\mathrm{Mn}$ ) in the fluid samples were measured by inductively coupled plasma (ICP) emission spectrophotometry. The analytical precision was estimated to be within $5 \%$ for each component. The alkalinity and $\mathrm{pH}$ and the concentrations of $\mathrm{SiO}_{2}$ and $\mathrm{NH}_{4}$ were analyzed onboard. The $\mathrm{pH}$ and alkalinity were determined using a $\mathrm{pH}$ meter by potentiometric titration with $0.1 \mathrm{M} \mathrm{HCl}$. The $\mathrm{SiO}_{2}$ and $\mathrm{NH}_{4}$ concentrations were measured by spectrophotometries of silicomolybdate complex and phenol blue, respectively. The analytical precisions were estimated to be within $0.5 \%$ for $\mathrm{pH}, 5 \%$ for alkalinity, and $7 \%$ for $\mathrm{SiO}_{2}$ and $\mathrm{NH}_{4}$. Parts of the results of these analyses have been reported elsewhere (Nakagawa et al., 2005). Dissolved B concentration was determined using a colorimetric technique involving a curcumin complex with a precision of $3 \%$. Dissolved $\mathrm{I}$ and $\mathrm{Br}$ concentrations were determined by ICP-MS with standard deviations less than 5\% (Muramatsu et al., 2007). The Al concentration was determined with the fluorometric method using Lumogallion (Obata et al., 2000) after diluting the samples with seawater of open ocean.

The concentrations of $\mathrm{CO}_{2}, \mathrm{CH}_{4}, \mathrm{H}_{2} \mathrm{~S}$, and $\mathrm{C}_{2} \mathrm{H}_{6}$ were determined by GC-TCD with $10 \%$ errors. The $\mathrm{H}_{2}$ concentration and its stable isotope ratio were determined by using a continuous-flow isotope ratio mass spectrometer (CF-IRMS: Kawagucci et al., 2010a). Carbon and hydrogen isotope ratios of $\mathrm{CH}_{4}$ were also determined by a CFIRMS (Popp et al., 1995; Umezawa et al., 2009) while Dual-Inlet IRMS technique was used for carbon isotope analysis of $\mathrm{CO}_{2}$. Stable hydrogen and carbon isotope ratios are represented by the generally-used linear $\delta$-notation in per-mil scales against the standards of VSMOW and PDB, respectively. The ${ }^{3} \mathrm{He} /{ }^{4} \mathrm{He}$ ratio was measured by a conventional noble gas mass spectrometer (Sano and Wakita, 1988; Sano et al., 2008). 


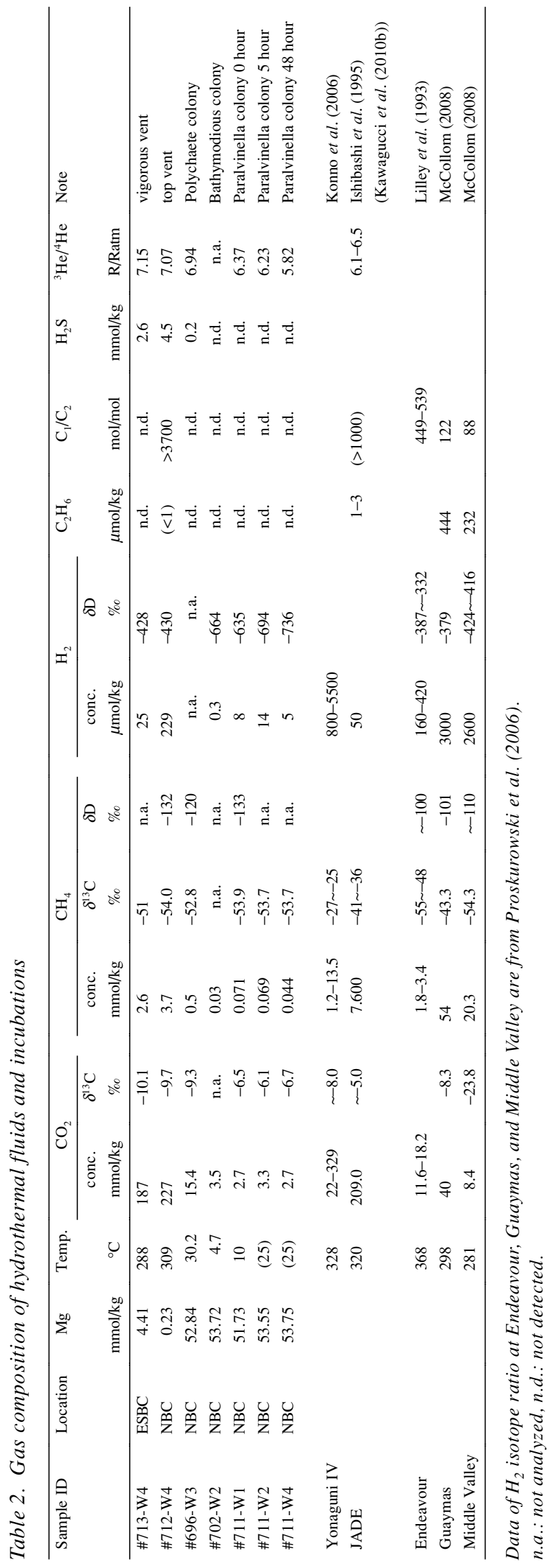

\section{RESUlTS AND DISCUSSION}

Major geochemistry

The major chemical composition of vent fluid demonstrated linear correlations against $\mathrm{Mg}$ concentration for each of the chimney sites, while the correlation pattern was different among the sampling years. Estimated endmember compositions using Mg-Element diagrams, represented by $y$-intercepts of least squares fits forcing lines to go through the ambient seawater composition (Von Damm et al., 1985), were listed in Table 1. The major chemical composition differed among the vents and among the years (Fig. 3). These results indicate that the vent fluid of each chimney site would be generated by two-endmember mixing between the vent fluid and the infiltrated seawater, but the chemical composition of endmember hydrothermal fluid and the mixing pattern would change temporally. The endmember $\mathrm{Cl}$ concentrations were ranged between 16-585 mmol/kg (cf., $\left.[\mathrm{Cl}]_{\text {seawater }}=560 \mathrm{mmol} / \mathrm{kg}\right)($ Table 1$)$, representing the significant phase-separation-controlled variation of hydrothermal fluid chemistry (Nakagawa et al., 2005).

Many of the vent fluids in the Iheya North field were Cl-depleted (Fig. 3a). The NBC vent fluids had relatively stable $\mathrm{Cl}$ contents and were close to that of the ambient seawater (Fig. 3a), while the $\mathrm{Cl}$ contents in the vent fluids became lower at chimney sites with increasing distance from the NBC site (Fig. 2b). This distribution pattern of the Cl-depleted hydrothermal fluids in a field was also observed in the Yonaguni Knoll IV field (Suzuki et $a l ., 2008)$. Hence, it is hypothesized that the subseafloor boiling (subcritical phase-separation) of hydrothermal fluid would induce the different mobility of different phases, and the vapor phase may further migrate to the exterior chimney sites. This may explain that the more Cl-depleted hydrothermal fluids are found at the exterior chimney sites and the Cl-enriched or -moderate fluids are distributed around the hydrothermal activity center, the NBC site. The more $\mathrm{Cl}$-enriched (brine) fluids may reside in hydrothermal reaction zone (Von Damm et al., 2005).

Other major components ( $\mathrm{K}, \mathrm{Na}, \mathrm{Ca}$, and so on) of the endmember fluids were correlated well with the $\mathrm{Cl}$ concentration (Fig. 4, Table 1), also supporting the boiling-controlled hydrothermal fluid chemistry. In addition, the almost constant Element/Cl ratio (Table 1) provided an estimated chemical composition of the source hydrothermal fluid that was the primary hydrothermal fluid prior to undergoing phase-separation and -segregation (Butterfield et al., 1994). The estimated endmember source fluid in the Iheya North field had high K, Li, B, I and $\mathrm{NH}_{4}$ contents and alkalinity relative to those in the typical MOR fields. In particular, the high $\mathrm{K}$ contents were an outstanding feature of the hydrothermal fluids in the Okinawa Trough (Kishida et al., 2004; Sakai et al., 1990b; 


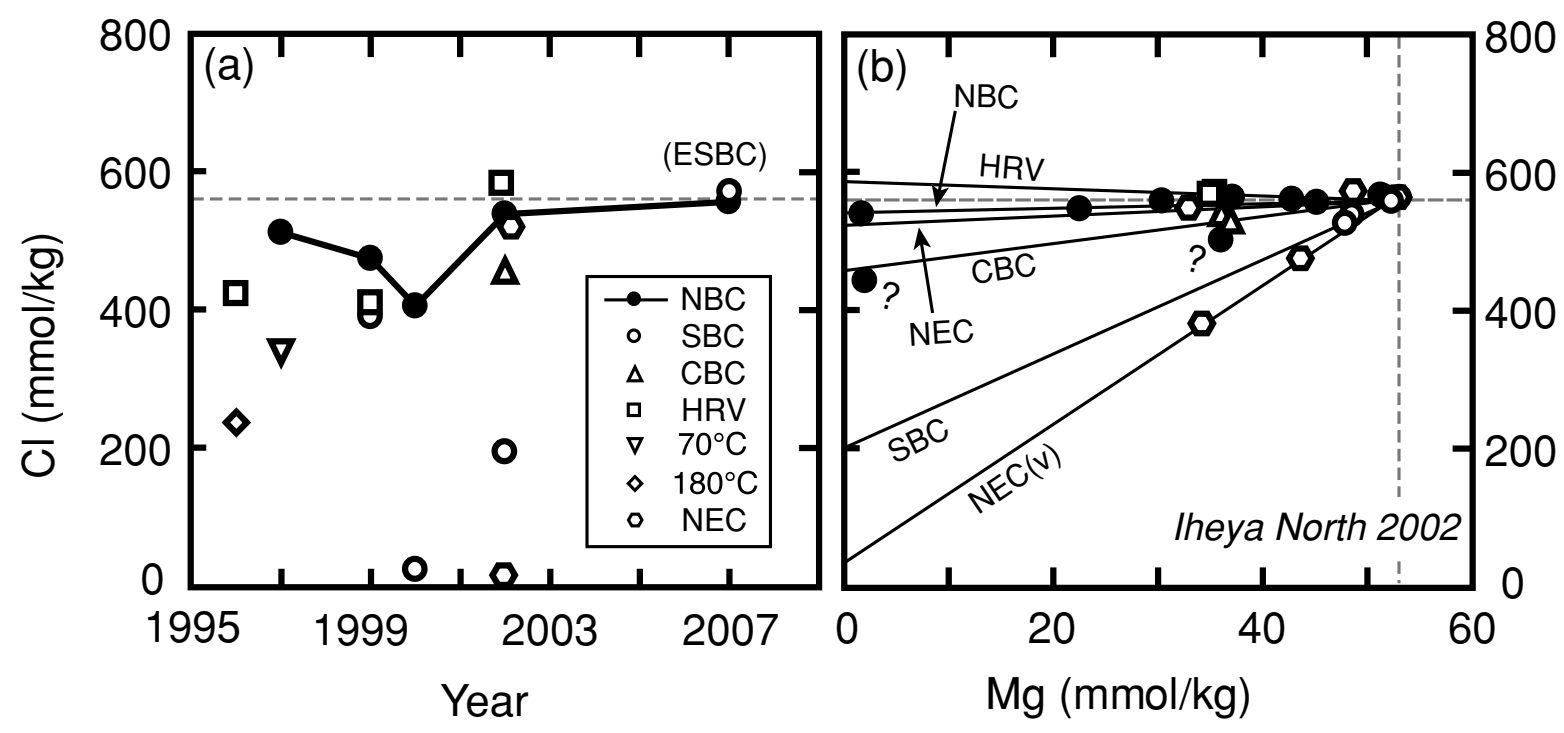

Fig. 3. (a) Estimated endmember-Cl concentrations of each vent and year and (b) measured $\mathrm{Mg}$ and Cl concentrations in 2002. Solid lines are least-square regressions for each vent passing through the seawater composition, while those with "NEC" and "NEC $(v)$ " respectively represent the regressions of some normal samples and the other anomalously vapor-enriched samples obtained from the NEC site. Dashed lines represent seawater values.

Suzuki et al., 2008) (Fig. 4). It has been pointed out that the high $\mathrm{K}$ contents in the hydrothermal fluids are typical in the arc-backarc hydrothermal systems due to the hydrothermal reaction with the K-enriched felsic rocks (Sakai et al., 1990b; Suzuki et al., 2008) although the sedimentary organic matters may serve as the other $\mathrm{K}$ source in the fluids (Seewald et al., 1994). The high I, B and $\mathrm{NH}_{4}$ contents and alkalinity are common features in the sediment-associated hydrothermal fluids (Gamo et al., 1991; Lilley et al., 1993; You et al., 1994). These chemical components are supplied from the sedimentary organic matters through thermal and/or biological degradation processes. The major chemical composition and its variation of the Iheya North hydrothermal fluids are consistent with the physical and chemical impacts of the host rocks, the sediments and the shallow water depth that was previously pointed to in the similar hydrothermal systems in the Okinawa Trough and in the sediments-associated settings.

\section{Gas geochemistry}

Gas composition Results of gas analyses are listed in Table 2. Low Mg concentrations of high temperature fluid samples (ID \#713-W4 and \#712-W4) allowed us to regard the observed gas compositions as the nearly endmember compositions. The high $\mathrm{CO}_{2}$ contents of 227 and $187 \mathrm{mmol} / \mathrm{kg}$ respectively in the NBC and ESBC fluids were notable. The $\delta^{13} \mathrm{C}$ values of $\mathrm{CO}_{2}$ were $-10.1 \%$ o and $-9.7 \%$ (Table 2, Fig. 5). Considering the stable carbon isotopic composition ranges of the ${ }^{13} \mathrm{C}$-depleted and

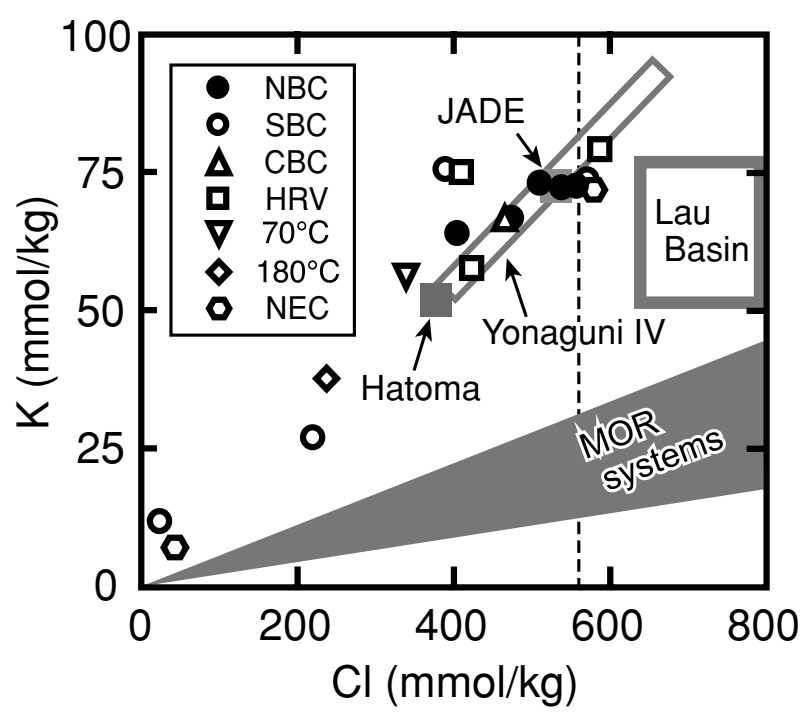

Fig. 4. Estimated endmember $C l$ and $-K$ concentrations. Data areas for JADE, Hatoma, Yonaguni IV, and Lau Basin hydrothermal fluids were respectively from Sakai et al. (1990b), Kishida et al. (2004), Suzuki et al. (2008), and Fouquet et al. (1991). A dashed vertical line indicates seawater Cl content.

-enriched magmatic $\mathrm{CO}_{2}(-9.3 \sim 0 \%$ : Blank et al., 1993; Takai et al., 2008b) and of the typical ${ }^{13} \mathrm{C}$-depleted thermogenic $\mathrm{CO}_{2}(-25 \sim-20 \%$ : Seewald et al., 1994), the extraordinary high concentration of $\mathrm{CO}_{2}$ in the Iheya North field would be largely derived from the magmatic $\mathrm{CO}_{2}$ 


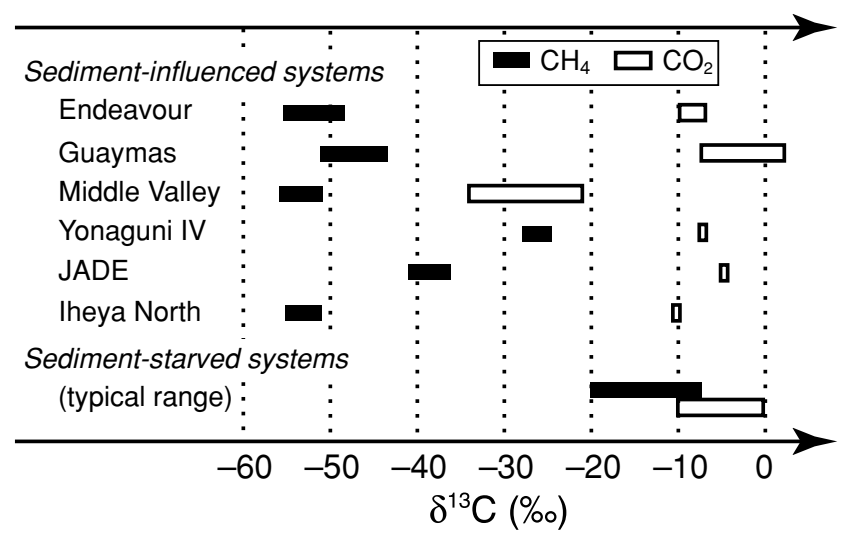

Fig. 5. Stable carbon isotope composition of $\mathrm{CH}_{4}$ and $\mathrm{CO}_{2}$ in hydrothermal fluids. The composition in the Yonaguni IV, JADE, and Iheya North are respectively from Konno et al. (2006), Ishibashi et al. (1995), and this study. The other data is from McCollom (2008) and therein.

input (Ishibashi et al., 1995; Lupton et al., 2008; Toki et al., 2008) rather than the thermogenic $\mathrm{CO}_{2}$ as previously suggested although the quantitative input of thermogenic $\mathrm{CO}_{2}$ was not yet excluded. The helium isotope ratios $\left(\left[{ }^{3} \mathrm{He} /{ }^{4} \mathrm{He}\right] /\left[{ }^{3} \mathrm{He} /{ }^{4} \mathrm{He}\right]_{\mathrm{atm}}\right)$ of high temperatures vent fluids were 7.15 and 7.07, indicating the potential mantlederived helium input (Lupton and Craig, 1975). A significant difference of $\mathrm{H}_{2}$ concentration between the NBC $(229 \mu \mathrm{mol} / \mathrm{kg})$ and ESBC $(25 \mu \mathrm{mol} / \mathrm{kg})$ fluids was observed (Table 2). However, the difference is very difficult to explain only by the fluid boiling and the preferential partition of insoluble gas components such as $\mathrm{H}_{2}, \mathrm{CH}_{4}$ and $\mathrm{He}$ in the $\mathrm{Cl}$-depleted fluids (Chiodini et al., 2001; Takai et al., 2008b) because the $\mathrm{CH}_{4}$ concentrations were relatively similar between the NBC and ESBC fluids (Table 2). Possible explanations are the microbial $\mathrm{H}_{2}$ consumption $\left(\mathrm{H}_{2}\right.$ depletion) and/or the additional $\mathrm{CH}_{4}$ input with little $\mathrm{H}_{2}$ in the subseafloor environments around ESBC site after the phase-separation and -partition process. Since the $\delta \mathrm{D}_{\mathrm{H} 2}$ values of the NBC and ESBC fluids (describe below) are almost identical (Table 1), the microbial $\mathrm{H}_{2}$ consumption seems to be not significant. On the contrary, the additional $\mathrm{CH}_{4}$ input is more likely as the liquid $\mathrm{CO}_{2}$ pools enriched with both $\mathrm{CH}_{4}$ and $\mathrm{H}_{2} \mathrm{~S}$ are probably widespread in the Okinawa Trough hydrothermal systems (Sakai et al., 1990b; Konno et al., 2006; Inagaki et al., 2006; Nunoura et al., 2010) and would serve as the $\mathrm{CH}_{4}\left(\mathrm{CO}_{2}\right.$ and $\left.\mathrm{H}_{2} \mathrm{~S}\right)$ sources. Thus, it is still just a speculation but may be possible that the ESBC hydrothermal fluid is additionally enriched with the gas components such as $\mathrm{CO}_{2}, \mathrm{H}_{2} \mathrm{~S}$ and $\mathrm{CH}_{4}$ by encountering the liquid $\mathrm{CO}_{2}$ pools somewhere in the subseafloor environments around ESBC site.

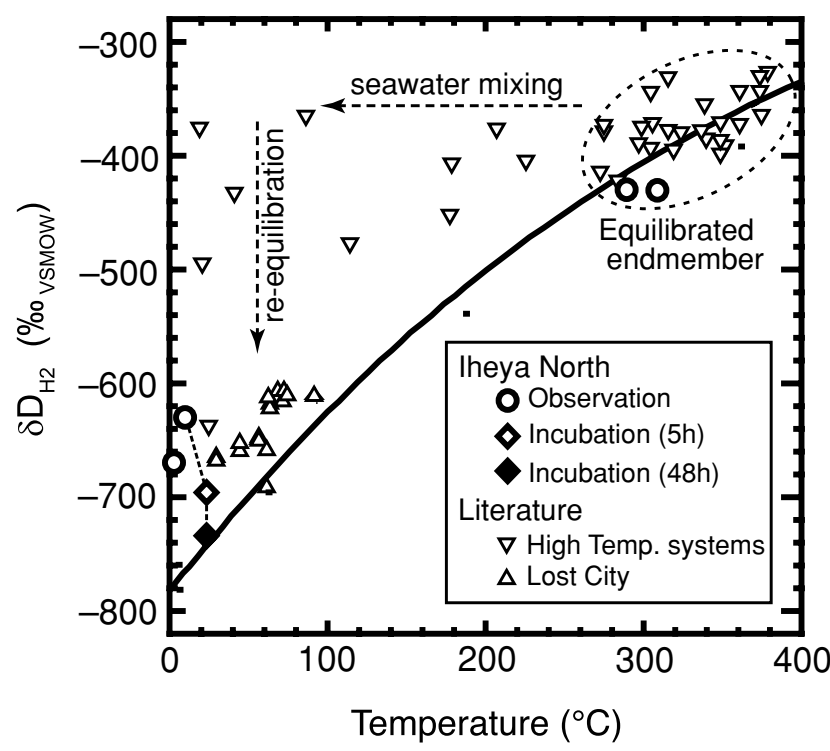

Fig. 6. Relationship between the $\delta D_{H 2}$ values and the fluid temperature at the sampling. Open circles represent the observed data in this study. Open and solid diamonds represent the results of 5 and 48 hours incubations, respectively. Open normal and inversed triangles indicate the previous data obtained from the high temperatures of hydrothermal fluids in the MOR hydrothermal systems (inversed) and the fluids from the Lost City hydrothermal field (normal) reported by Proskurowski et al. (2006) and Kawagucci et al. (2010a). The $\delta D_{H 2}$ values at the isotope equilibrium between $\mathrm{H}_{2}$ and $\mathrm{H}_{2} \mathrm{O}$, calculated from the temperature-dependent isotope fractionation factor (Horibe and Craig, 1995) assuming $\delta D_{H 2 O}=+0 \%$, are also shown as a curve. Fluid cooling and the subsequent isotope equilibrium reaction respectively shift the plot to the left and down.

Microbial modification of stable isotope ratio of $\mathrm{H}_{2}$ The stable isotope ratios of $\mathrm{H}_{2}\left(\delta \mathrm{D}_{\mathrm{H} 2}\right)$ in the obtained hightemperature fluids were around $-430 \%$ o (Table 2). It is known that the $\delta \mathrm{D}_{\mathrm{H} 2}$ value in high-temperature hydrothermal fluid is dominated by the hydrogen isotope equilibrium between $\mathrm{H}_{2}$ and $\mathrm{H}_{2} \mathrm{O}$ (Proskurowski et al., 2006) that induces temperature-dependent fractionation between deuterium and hydrogen (Horibe and Craig, 1995) as following reactions:

$$
\begin{aligned}
& \mathrm{H}_{2} \leftrightarrow 2 \mathrm{H}^{+}+2 \mathrm{e}^{-} \\
& \mathrm{H}_{2} \mathrm{O} \leftrightarrow \mathrm{H}^{+}+\mathrm{OH}^{-} \\
& \mathrm{HD}+\mathrm{H}_{2} \mathrm{O} \leftrightarrow \mathrm{H}_{2}+\mathrm{HDO} .
\end{aligned}
$$

The relationship between the observed $\delta \mathrm{D}_{\mathrm{H}_{2}}$ values and the measured maximum temperature during the sampling was analyzed (Fig. 6) in order to examine the isotopic equilibrium between $\mathrm{H}_{2}$ and $\mathrm{H}_{2} \mathrm{O}$ at the venting fluid tem- 
perature. The $\delta \mathrm{D}_{\mathrm{H} 2}$ values $(-430 \%$ and $-428 \%$ ) were comparable with $-405 \%$ o corresponding to an equilibrated $\delta \mathrm{D}_{\mathrm{H} 2}$ value based on the calculation from the isotope fractionation factor (Horibe and Craig, 1995) assuming $\delta \mathrm{D}_{\mathrm{H} 2 \mathrm{O}}=+0 \%$ o (hydrothermal $\delta \mathrm{D}_{\mathrm{H} 2 \mathrm{O}}=+0 \pm 5 \%$ : Shanks III et al., 1995) in the case when the fluid temperature is $300^{\circ} \mathrm{C}$. This indicates that the $\delta \mathrm{D}_{\mathrm{H} 2}$ values in the high temperature fluids in the Iheya North field were dominated by the equilibrium at the temperature of hydrothermal endmember.

The lower temperature fluids obtained from the animal colonies showed significantly lower $\delta \mathrm{D}_{\mathrm{H} 2}$ values $(<-635 \%)$ than those in high temperature fluids $(-430 \%)$. Because a negligible $\delta \mathrm{D}_{\mathrm{H} 2}$ change was expected at a mixing between hydrothermal fluid and ambient seawater due to little $\mathrm{H}_{2}$ content in deep-sea seawater $(<0.1 \mathrm{nmol} / \mathrm{kg}$ : Moore et al., 2009), the lower $\delta \mathrm{D}_{\mathrm{H} 2}$ values should result from some processes other than the mixing. The isotope exchange reaction (rxn. 1) after the fluid cooling can make a $\delta \mathrm{D}_{\mathrm{H} 2}$ value decreasing from that of the high temperature fluid, because of decreasing the equilibrated $\delta \mathrm{D}_{\mathrm{H} 2}$ value with decreasing temperature (Fig. 6) due to larger isotope fractionation factor at lower temperature (Horibe and Craig, 1995). As opposed that the abiotic isotope exchange reaction rate drastically decreases at lower temperatures (e.g., Campbell et al., 2009), microbial $\mathrm{H}_{2}$ metabolisms are known to catalyze the isotope exchanging (Vignais, 2005) even at temperatures as low as $30^{\circ} \mathrm{C}$ (Romanek et al., 2003; Valentine et al., 2004a). The lower $\delta \mathrm{D}_{\mathrm{H} 2}$ values in the low temperature fluid than those in the high temperature fluid were observed in other hydrothermal fields and considered as results from subseafloor microbial $\mathrm{H}_{2}$-consuming or -producing activities (Kawagucci et al., 2010a). Microbial $\mathrm{H}_{2}$-metabolisms in the low temperature hydrothermal environment can account for the variation of $\delta \mathrm{D}_{\mathrm{H} 2}$ values in the Iheya North fluids. In fact, the onboard incubation experiment using the Paralvinella colony water indicated that $\delta \mathrm{D}_{\mathrm{H} 2}$ values shifted to the equilibrated $\delta \mathrm{D}_{\mathrm{H} 2}$ value at $25^{\circ} \mathrm{C}$ during the incubation (Fig. 6, Table 2). Although a quantitative relation between the $\delta \mathrm{D}_{\mathrm{H} 2}$ change and the microbial $\mathrm{H}_{2}$ metabolisms has been poorly understood, the microbial $\delta \mathrm{D}_{\mathrm{H} 2}$ change may be consistent with the previous microbiological characterization (Nakagawa et al., 2005), pointing to the abundant hydrogenotrophic and hydrogenogenic metabolisms in the microbial communities in the Iheya North hydrothermal field.

\section{Methane}

Biogenic methane The $\mathrm{CH}_{4}$ concentrations in the hightemperature fluids were $\sim 3 \mathrm{mmol} / \mathrm{kg}$ (Table 2). The milimolar level of $\mathrm{CH}_{4}$ contents are common in the sedimentsassociated hydrothermal fluids (Lilley et al., 1993; Pearson et al., 2005; Cruse and Seewald, 2006;

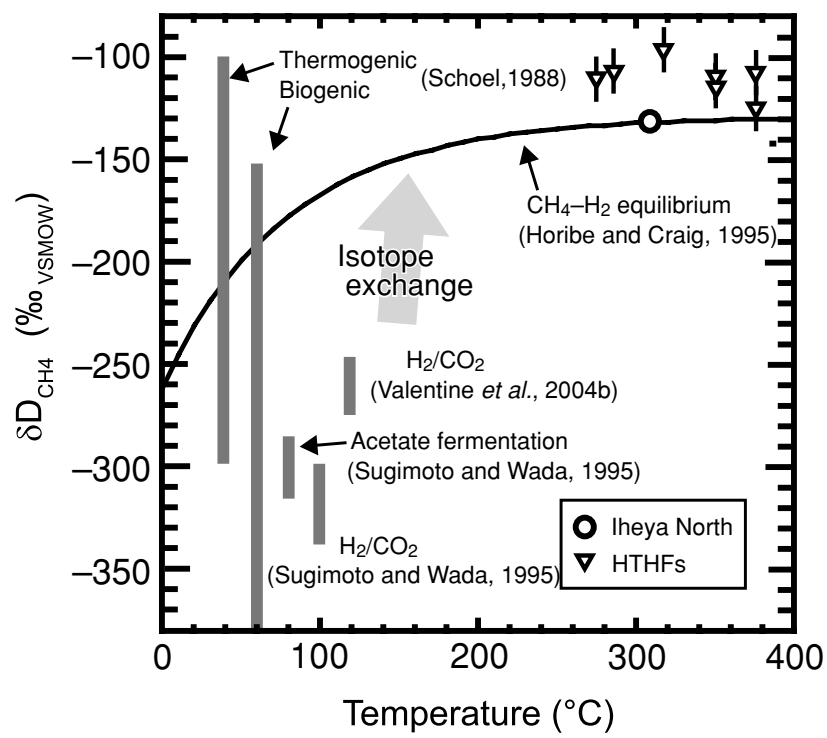

Fig. 7. Relationship between the $\delta D_{\mathrm{CH} 4}$ values and the fluid temperature at the sampling. An open circle indicates the data in this study. Open triangles represent the previous data obtained from the high temperatures of hydrothermal fluids in the MOR hydrothermal systems by Proskurowski et al. (2006). The $\delta D_{\mathrm{CH} 4}$ values at the isotope equilibrium between $\mathrm{CH}_{4}$ and $\mathrm{H}_{2}$, calculated from the temperature-dependent isotope fractionation factors (Horibe and Craig, 1995) assuming the isotope equilibrium between $\mathrm{H}_{2}$ and $\mathrm{H}_{2} \mathrm{O}$ at $\delta D_{\mathrm{H} 2 \mathrm{O}}=0 \%$ ( shown in Fig. 6), are also shown as a curve. Gray bars represent reported ranges of $\delta D_{\mathrm{CH} 4}$ values as thermogenic and biogenic methane by Schoell (1988), Sugimoto and Wada (1995), and Valentine et al. (2004b).

McCollom, 2008) including Okinawa Trough hydrothermal fluids (Chiba et al., 1993; Ishibashi et al., 1995; Konno et al., 2006). The abundant hydrothermal fluid $\mathrm{CH}_{4}$ has been considered to be a thermogenic origin (via thermal degradation of sedimentary organic matters) (Ishibashi et al., 1995; Lilley et al., 1993) and to be in some cases a biogenic origin (via microbial methanogenesis) (Cruse and Seewald, 2006). The observed $\delta^{13} \mathrm{C}_{\mathrm{CH} 4}$ values in the Iheya North fluids were $-54.0 \%$ and $-51.0 \%$. These values are among the most $\delta^{13} \mathrm{C}$-depleted values so far observed in the hydrothermal fluids (Fig. 5). A trace amount of ethane $(<1 \mu \mathrm{mol} / \mathrm{kg})$ was detected in a hydrothermal fluid, resulting in a $C_{1} / C_{2}$ ratio of $>3.7 \times 10^{3}$. Concentration of $\mathrm{H}_{2}(<200 \mu \mathrm{mol} / \mathrm{kg})$ is not so high relative to those in other felsic-rock based fields (e.g., Takai et al., 2008b) and results in a $\mathrm{H}_{2} / \mathrm{CH}_{4}$ ratio lower than 0.07 . While $\mathrm{H}_{2} / \mathrm{CH}_{4}$ ratios in sedimentfree fields are typically higher than 1 , those in sedimentassociated fields are lower than 1 (Kawagucci et al., $2010 \mathrm{~b}$ ). In addition, the stable hydrogen isotope ratio of $\mathrm{CH}_{4}\left(\delta \mathrm{D}_{\mathrm{CH} 4}\right)$ was $-132 \%$, comparable with those so far 
observed in both sediment-starved and -associated hydrothermal systems (-125 -96\%o: Welhan and Craig, 1983; Proskurowski et al., 2006) (Fig. 7).

The abiotic $\mathrm{CH}_{4}$ input is estimated to be quite low based on the $\mathrm{CH}_{4}$ contents in the hydrothermal fluids obtained from typical sediments-starved, arc-backarc (felsic-rock based) hydrothermals systems in the Suiyo Seamount (Toki et al., 2008) and in the Lau Basin (Takai et al., 2008b). Thus, it is obvious that the Iheya North hydrothermal fluid $\mathrm{CH}_{4}$ should be derived from the thermogenic or the biogenic process or the both processes. The $\delta^{13} \mathrm{C}_{\mathrm{CH} 4}$ values $(<-51 \%)$ are lower than the $\delta^{13} \mathrm{C}_{\mathrm{CH} 4}$ value range of so-called "thermogenic $\mathrm{CH}_{4}$ " (-50 -20\%o: Whiticar, 1999) and than the values of the experimentally produced $\mathrm{CH}_{4}\left(\delta^{13} \mathrm{C}_{\mathrm{CH} 4}=-24 \sim-21 \%\right.$ ) from the in situ Guaymas Basin sediments $\left(\delta^{13} \mathrm{C}_{\text {organic }}=-17 \%\right.$ ) at $325^{\circ} \mathrm{C}$ and 500 bar (Seewald et al., 1994). Thus, the stable carbon isotopic composition of the Iheya North fluid $\mathrm{CH}_{4}$ cannot be attained only by the thermogenic source of $\mathrm{CH}_{4}$. Rather, the more predominant contribution of the ${ }^{13} \mathrm{C}$-depleted $\mathrm{CH}_{4}$ to the hydrothermal fluid $\mathrm{CH}_{4}$ should be predicted. Based on several experiments of carbon isotopic fractionations by hydrogenotrophic and aceticlastic methanogens, the kinetic isotopic effects have been estimated to be -10 to $-50 \%$ for the hydrogenotrophic methanogens (e.g., House et al., 2003; Valentine et al., 2004b; Penning et al., 2005; Takai et al., 2008a) and approx. $-20 \%$ for the aceticlastic methanogens (e.g., Gelwicks et al., 1994). In the case of the Okinawa Trough, the $\delta^{13} \mathrm{C}$ values of the organic carbons and the derivative acetate and $\mathrm{CO}_{2}$ in the sediments are all assumed to be $-30 \sim-20 \%$ due to the primitive origins of marine planktonic and terrestrial plant productions, while the $\delta^{13} \mathrm{C}$ value of seawater bicarbonate is $\sim 0 \%$. Thus, to yield the Iheya North fluid $\mathrm{CH}_{4}$ of which $\delta^{13} \mathrm{C}_{\mathrm{CH} 4}$ is totally lower than $-51 \%$, most of the hydrothermal fluid $\mathrm{CH}_{4}$ should be derived from the hydrogenotrophic methanogenesis using $\mathrm{CO}_{2}$ derived from sedimentary organic carbons.

The high $\mathrm{C}_{1} / \mathrm{C}_{2}$ ratio of $>3.7 \times 10^{3}$ also supports the generation of source $\mathrm{CH}_{4}$ via the microbial methanogenesis. When the $\mathrm{C}_{1} / \mathrm{C}_{2}$ ratios of biogenic gases and thermogenic gases are respectively assumed to be $10^{4}$ (Vogel et al., 1982; Belay and Daniels, 1988) and $10^{2}$ (Cruse and Seewald, 2006; McCollom, 2008), the $\mathrm{C}_{1} / \mathrm{C}_{2}$ ratio of $>3.7 \times 10^{3}$ in the Iheya North fluid $\mathrm{CH}_{4}$ indicates that more than $97 \%$ of $\mathrm{CH}_{4}$ are provided from microbial methanogenesis. Furthermore, the relatively low $\mathrm{H}_{2}$ concentration $(<200 \mu \mathrm{mol} / \mathrm{kg})$ may be a signature that the thermogenic gases $\left(\mathrm{CH}_{4}, \mathrm{CO}_{2}\right.$ and $\left.\mathrm{H}_{2}\right)$ via the thermal degradation of organic matters are much less incorporated into the Iheya North hydrothermal fluids because the $\mathrm{H}_{2}$ concentrations are sometime more than $1 \mathrm{mmol} / \mathrm{kg}$ in the sediments-covered hydrothermal systems (Cruse and Seewald, 2006; McCollom, 2008). The hydrothermal ex- periment using the in situ sediments of the Guaymas Basin has also estimated that more than $1 \mathrm{mmol} / \mathrm{kg}$ of $\mathrm{H}_{2}$ can be produced via the hydrothermal degradation of the sedimentary organic matters (Seewald et al., 1994).

The stable isotopic compositions of hydrogen and carbon in the $\mathrm{CH}_{4}$ can be affected not only at the time of the generation but also during the transportation in the hydrothermal fluids. The $\delta^{13} \mathrm{C}_{\mathrm{CH} 4}$ value of the hydrothermal fluid $\mathrm{CH}_{4}$ is potentially controlled by the carbon isotope equilibrium through the following chemical equilibrium:

$$
\mathrm{CO}_{2}+4 \mathrm{H}_{2} \leftrightarrow \mathrm{CH}_{4}+2 \mathrm{H}_{2} \mathrm{O}
$$

If full carbon isotope equilibrium of $\mathrm{CH}_{4}$ with $\mathrm{CO}_{2}$ $\left(\delta^{13} \mathrm{C}_{\mathrm{CO} 2}=-10 \%\right.$ ) at the vent fluid temperature of $310^{\circ} \mathrm{C}$ is assumed, a $\delta^{13} \mathrm{C}_{\mathrm{CH} 4}$ value in the Iheya North fluid should be higher than $-40 \%$ (Horita, 2001). This assumption is clearly inconsistent with the observed $\delta^{13} \mathrm{C}_{\mathrm{CH} 4}$ value of lower than $-51 \%$. Such disequilibrium in carbon isotopes has been observed in other sedimentassociated hydrothermal systems (e.g., Cruse and Seewald, 2006; McCollom, 2008). Abiotic methane production through the rxn. 2 is thermodynamically unfavorable in the case of the Iheya North hydrothermal system due especially to the relatively low $\mathrm{H}_{2}$ concentration (McCollom, 2008). Thus the carbon isotope equilibrium between $\mathrm{CH}_{4}$ and $\mathrm{CO}_{2}$ would be negligible during the hydrothermal circulation after the $\mathrm{CH}_{4}$ generation and incorporation. In addition, it has been suggested in the Yonaguni Knoll IV hydrothermal fluids that the phaseseparation and -segregation processes have little effect (at most 3\%o) on the stable carbon isotope fractionation of $\mathrm{CH}_{4}$ (e.g., Konno et al., 2006). Thus, the $\delta^{13} \mathrm{C}_{\mathrm{CH} 4}$ values of the Iheya North hydrothermal fluid $\mathrm{CH}_{4}$ would represent the stable isotopic information at the time of generation of $\mathrm{CH}_{4}$ sources.

The $\delta \mathrm{D}$ value of $\mathrm{CH}_{4}\left(\delta \mathrm{D}_{\mathrm{CH} 4}\right)$ initially reflects the $\delta \mathrm{D}$ values of substrate $\left(\mathrm{H}_{2} \mathrm{O}\right.$ and Org- $\left.\mathrm{H}\right)$ and the kinetic isotope fractionations on abiotic and biotic methanogenesis (e.g., Sugimoto and Wada, 1995; Valentine et al., 2004b), potentially representing a wide range of $\delta \mathrm{D}_{\mathrm{CH} 4}$ values (Fig. 7: e.g., Schoell, 1980). However, all the $\delta \mathrm{D}_{\mathrm{CH} 4}$ values determined so far in the hydrothermal fluids including the Iheya North fluids have fallen into a narrow range (-130 -96\%o: Welhan and Craig, 1983; Proskurowski et al., 2006) regardless of the types of hydrothermal systems. This observation points that a common process dominates to control the $\delta \mathrm{D}_{\mathrm{CH} 4}$ values of the hydrothermal fluid $\mathrm{CH}_{4}$. The hydrogen isotope equilibrium between $\mathrm{H}_{2} \mathrm{O}-\mathrm{H}_{2}-\mathrm{CH}_{4}$ in the high temperatures fluids would be the most likely process. The isotope systematics could be described by two of the isotopic equilibria between $\mathrm{H}_{2} \mathrm{O}-$ $\mathrm{H}_{2}$ and $\mathrm{H}_{2}-\mathrm{CH}_{4}$, as seen in the $\delta \mathrm{D}_{\mathrm{H} 2}$ value via the rxn. 1 
and a following isotope equilibrium reaction:

$$
\mathrm{CH}_{4}+\mathrm{HD} \leftrightarrow \mathrm{CH}_{3} \mathrm{D}+\mathrm{HH} .
$$

If it is assumed that (or since) the isotopic equilibria proceed faster between $\mathrm{H}_{2}-\mathrm{H}_{2} \mathrm{O}$ than between $\mathrm{CH}_{4}-\mathrm{H}_{2}$ (complex reactions in detail) in the high temperatures hydrothermal fluids, the $\delta \mathrm{D}_{\mathrm{CH} 4}$ values of the hydrothermal fluid $\mathrm{CH}_{4}$ can be calculated using the thermally equilibrated $\delta \mathrm{D}_{\mathrm{H} 2}$ values according to rxn. 3. Indeed, all the known $\delta \mathrm{D}_{\mathrm{CH} 4}$ range of hydrothermal fluid $\mathrm{CH}_{4}$ is comparable to the thermal isotopic equilibrium range calculated from the fluid temperatures and the temperature-dependent isotope fractionation factors on the $\mathrm{CH}_{4}-\mathrm{H}_{2}$ and $\mathrm{H}_{2}-\mathrm{H}_{2} \mathrm{O}$ equilibriums (Horibe and Craig, 1995) assuming $\delta \mathrm{D}_{\mathrm{H} 2 \mathrm{O}}$ $=+0 \%$ (Shanks III et al., 1995) (Fig. 7). This result suggests that the $\delta \mathrm{D}_{\mathrm{CH} 4}$ values of the hydrothermal fluid may be controlled by the hydrogen isotope equilibrium between $\mathrm{H}_{2} \mathrm{O}-\mathrm{H}_{2}-\mathrm{CH}_{4}$. Given that the hydrogen isotope equilibrium between $\mathrm{CH}_{4}$ and $\mathrm{H}_{2}$ at around $300^{\circ} \mathrm{C}$ needs a time longer than ten hours even at the experimental condition using a Ni-Thoria catalyst which effectively activates the rxn. 2 (Horibe and Craig, 1995), the equilibrium under subseafloor hydrothermal environment should take a time longer than ten hours. In contrast, hydrothermal fluid upwelling velocity $(1 \mathrm{~m} / \mathrm{sec}$ : Schultz and Elderfield, 1999) and generally-regarded reaction zone depth (sub-kilometers to several kilometers) provides an estimated fluid residence time at fluid discharging stage as short as an hour. The significantly longer time for establishing the isotope equilibrium than the time for fluid upwelling suggests that the isotope equilibrium occurred more likely at deep reaction zone rather than the fluid discharging stage. Apparent consistency of $\delta \mathrm{D}_{\mathrm{CH} 4}$ values between a part of the proposed thermogenic range (Schoell, 1980) and the observed hydrothermal range (Fig. 7) was probably circumstantial because of similar $\delta \mathrm{D}_{\mathrm{CH} 4}$ values observed even in sediment-starved hydrothermal systems (Logatchev and EPR $21^{\circ} \mathrm{N}$ : Welhan and Craig, 1983; Proskurowski et al., 2006). However, a difference among the observed hydrothermal $\delta \mathrm{D}_{\mathrm{CH} 4}$ values is small $(\sim 34 \%$ o) but significant (analytical errors of $\sim 10 \%$ ) so that the other factors controlling the $\delta \mathrm{D}_{\mathrm{CH} 4}$ values than the isotopic equilibriums at endmember hydrothermal temperatures might be involved for hydrothermal $\delta \mathrm{D}_{\mathrm{CH} 4}$ values. In any cases, the use of $\delta \mathrm{D}_{\mathrm{CH} 4}$ value to the discussion about the origin of hydrothermal methane may bring misunderstanding in this time. In other words, the deviation between the observed hydrothermal $\delta \mathrm{D}_{\mathrm{CH} 4}$ values and the biogenic $\delta \mathrm{D}_{\mathrm{CH} 4}$ range reported previously (Fig. 7: Schoell, 1980; Sugimoto and Wada, 1995; Valentine et al., 2004b) does not deny biogenic origin of methane in the Iheya North hydrothermal field.

Based on the compositional and isotopic properties of the hydrothermal fluid $\mathrm{CH}_{4}$ and other gas components in the Iheya North field, it is very likely that most $\mathrm{CH}_{4}$ should be produced by microbial methanogenesis prior to the high temperatures hydrothermal reaction probably utilizing $\mathrm{H}_{2}$ and $\mathrm{CO}_{2}$ which are provided from the sedimentary organic matters by functions of co-existing fermentative microorganisms. This generation model of hydrothermal fluid $\mathrm{CH}_{4}$ in the Iheya North field would be completely different from the case in another Okinawa Trough hydrothermal system, the Yonaguni Knoll IV field (Konno et al., 2006). In the Yonaguni Knoll IV field, the $\mathrm{CH}_{4}$ concentrations in the fluids are similar with those in the Iheya North field while the higher $\mathrm{H}_{2}$ concentrations $(>1$ $\mathrm{mmol} / \mathrm{kg})$ and more ${ }^{13} \mathrm{C}$-enriched $\mathrm{CH}_{4}\left(\delta^{13} \mathrm{C}=-27 \sim\right.$ $-24 \%$ ) are found than in the Iheya North field (Konno et al., 2006). As already discussed above, these compositional and isotopic properties of the hydrothermal gas components in the Yonaguni Knoll IV field suggest that the hydrothermal fluid $\mathrm{CH}_{4}$ would be derived from the thermal degradation of the sedimentary organic matters by the high temperatures hydrothermal fluid flow in the sediments. It is still uncertain why the two Okinawa Trough hydrothermal fields have different generation and incorporation mechanisms of the hydrothermal fluid $\mathrm{CH}_{4}$. However, it would be important to know where the $\mathrm{CH}_{4}$ generation and incorporation occur in the hydrothermal circulation processes.

Microbial methanogenesis at recharge zone The potentially significant contribution of microbial methanogenesis to the hydrothermal fluid $\mathrm{CH}_{4}$ has been suggested also at two sediment-covered systems, the Middle Valley field (Cruse and Seewald, 2006) and the Guaymas Basin field (Pearson et al., 2005). These studies have also presumed that the generation and incorporation of microbially produced $\mathrm{CH}_{4}$ should occur at the time prior to the hydrothermal reaction and the fluid discharging stages in the whole fluid circulation, that is the recharging stage of source fluids (Pearson et al., 2005; Cruse and Seewald, 2006). However, since the identification of practical location of hydrothermal fluid recharging paths is quite difficult without any of the geophysical surveys for the subseafloor sedimentary and crustal structures, the direct geochemical and microbiological evidences have been not yet obtained in any of the hydrothermal systems. In the Iheya North field, more than 40 DSV and ROV seafloor observations have been conducted and the seafloor structures are relatively well elucidated. In addition, several coring expeditions and geophysical surveys (e.g., heat flow distribution and seismic reflection analyses) have been conducted for proposing a future drilling expedition by Integrated Ocean Drilling Program (IODP). Thus, the potential fluid recharging areas hosting the hydrogenotrophic methanogenesis have been hypothesized to be either in the valley-filling deposits of 
the Central Valley in the Iheya North Knoll or in the basin-filling sediments around the Iheya North Knoll (IODP 601-Full3 proposal: http://www.iodp.org/600/). In lights of compositional and isotopic characteristics of gaseous carbons in the Iheya North hydrothermal fluids and the carbon mass balance between the hydrothermal fluids and the organic carbon potential in the Central Valley of the Iheya North Knoll, we try to draw an implication of the hydrothermal recharging area for the Iheya North field.

First, we estimate the $\mathrm{CH}_{4}$ emitting flux $\left(F_{\mathrm{CH} 4}\right)$ by the discharging hydrothermal fluids using a following equation:

$$
F_{\mathrm{CH} 4}=[\text { Conc. }] \times[\text { Area }] \times[\text { Vel. }] \times\left[\mathrm{N}_{\mathrm{vent}}\right] \times[\mathrm{L} / \mathrm{H}]
$$

where [Conc.], [Area], [Vel.], $\left[\mathrm{N}_{\mathrm{vent}}\right]$, and $[\mathrm{L} / \mathrm{H}]$ represent the endmember concentration of $\mathrm{CH}_{4}$, the average area of orifice of a vent, the average flow velocity of a venting fluid, the numbers of vent orifices, and the contribution factor for the $\mathrm{CH}_{4}$ flux between diffusing hydrothermal fluids and high temperatures fluids, respectively. The [Conc.] is determined to be $3[\mathrm{mmol} / \mathrm{L}]$. The [Area] is estimated by the seafloor observation $(\sim 2 \mathrm{~cm}$ in radius of a vent orifice) to be $12\left[\mathrm{~cm}^{2}\right]$. The [Vel.] is set to be $1[\mathrm{~m} / \mathrm{sec}]$ by the seafloor observation, which is equivalent to the velocity previously reported for other hydrothermal vents (Schultz and Elderfield, 1999). The high temperatures hydrothermal fluid vent sites are found at the NBC (two), ESBC, SBC and CBC, and thus the $\left[\mathrm{N}_{\text {vent }}\right]$ is 5. The diffusing hydrothermal fluids are recognized to convect more than one order of magnitude greater than the high temperature fluids (Elderfield and Schultz, 1996). Since numerous diffusing flow sites are found in the Iheya North field, the $[\mathrm{L} / \mathrm{H}]$ for the Iheya North field should be $>20$. These estimations lead to $F_{\mathrm{CH} 4}$ of $1.14 \times$ $10^{7}$ [mol/year].

Second, the organic carbon potential of the valleyfilling deposits in the Central Valley $\left(C_{\text {pot }}\right)$ is calculated by a following presumptive equation:

$$
C_{\text {pot }}=[\text { Vol. }] \times[\text { Density }] \times[\text { TOC }] \times 1 / 12
$$

where the [Vol.] is the total valley-filling deposit volume, the [Density] is a density of the deposit and the [TOC] is a total organic carbon content of deposit. The [Vol.] is calculated from the apparent seafloor area of the Central Valley as $2000 \mathrm{~m} \times 2000 \mathrm{~m}$ (Fig. 2a) and the deposit depth of $300 \mathrm{~m}$ with an assumption of a reverse cone shape of valley-filling deposit. It is calculated to be $3.14 \times 10^{8}$ $\left[\mathrm{m}^{3}\right]$. The [Density] and [TOC] are determined for the pumicious deposit obtained from the Central Valley and are $2\left[\mathrm{~g} / \mathrm{cm}^{3}\right]$ and $\sim 1 \times 10^{-5}[\mathrm{~g} / \mathrm{g}]$, respectively. These values lead to $C_{\text {pot }}$ of $5.23 \times 10^{8}\left[\mathrm{~mol}-\mathrm{CH}_{4}\right]$.
The calculated $C_{\text {pot }}$ value corresponds to maintain the $F_{\mathrm{CH} 4}$ for 46 years. This value is highly improbable as following reasons. It is 15 years since the Iheya North field is discovered in 1995 (Monma et al., 1996) and the hydrothermal activity still continues. The enormous hydrothermal mound structures and the prosperous ventendemic animal colonies at the time of discovery suggested that the hydrothermal activity had continued for several tens years before the discovery. In addition, the calculation is based on impractial assumptions: the whole organic carbons in the valley-filling deposits convert to $\mathrm{CH}_{4}$ without any conversion to $\mathrm{CO}_{2}$ and other inorganic and organic carbons and the whole produced $\mathrm{CH}_{4}$ is entrained by hydrothermal fluids without any loss during the transportation. These impractical assumptions bring a difference between the $C_{\text {pot }}$ and actually-produced methane from valley-filling organic carbon, which we should compare to the $F_{\mathrm{CH} 4}$, and the difference means that the term to maintain the $F_{\mathrm{CH} 4}$ ( $\sim 6$ years) should be overestimated. It seems unlikely, therefore, that the hydrothermal fluid $\mathrm{CH}_{4}$ in the Iheya North field is derived from the microbial methanogenesis associated with the organic carbons in the valley-filling deposits in the Central Valley of the Iheya North Knoll.

Considering the carbon mass balance of the hydrothermal fluid $\mathrm{CH}_{4}$, it seems more likely that the microbial methanogenesis associated with the organic carbons should occur not only in the Central Valley, but also in the spatially abundant and widespread basin-filling sediments surrounding the Iheya North Knoll, and the microbially produced $\mathrm{CH}_{4}$ would be recharged together with the source fluid into the hydrothermal reaction and discharging stages of circulation. This "Microbial Methanogenesis at Recharge area in hydrothermal circulation" (MMR) model in the Iheya North field is hypothesized based on the hydrothermal gas chemistry. Nevertheless, this MMR model is not conflict with other chemical components such as high $\mathrm{I}, \mathrm{B}$ and $\mathrm{NH}_{4}$ contents and alkalinity because these were considered as results from decomposition of sedimentary organic matter (Gamo et al., 1991; Lilley et al., 1993; You et al., 1994) possibly independent from thermal or biological processes. The MMR model is also consistent with the interpretation of the $\delta \mathrm{D}_{\mathrm{CH} 4}$ values in hydrothermal fluids that the $\mathrm{CH}_{4}$ produced at the recharge zone had initially shown $\delta \mathrm{D}_{\mathrm{CH} 4}$ value within biogenic range (-350\%o--250\%o: Sugimoto and Wada, 1995; Valentine et al., 2004b) and the hydrogen isotope exchanges among $\mathrm{H}_{2} \mathrm{O}-\mathrm{H}_{2}-\mathrm{CH}_{4}$ at high temperature reaction zone made the $\delta \mathrm{D}_{\mathrm{CH} 4}$ value to the equilibrated value of $-130 \%$ (Fig. 7).

\section{IMPLICATION}

The MMR model in the Iheya North field may also 
provide an important implication for the generation and incorporation of hydrothermal fluid $\mathrm{CH}_{4}$ in other deepsea hydrothermal systems in the Okinawa Trough (e.g., the JADE field of the Izena Hole) (Ishibashi et al., 1995) and in the Juan de Fuca Ridge and the Guaymas Basin (Lilley et al., 1993; Pearson et al., 2005; Cruse and Seewald, 2006; McCollom, 2008). For instance, the Endeavour field is known to occur in the sediments-starved axial valley in the Juan de Fuca Ridge (Delaney et al., 1992) while the hydrothermal fluids represent the sediment-influenced characteristics (Lilley et al., 1993; Cruse and Seewald, 2010). The compositional and isotopic characteristics of gas components, high $\mathrm{CH}_{4}$ concentrations $(1.8-3.4 \mathrm{mmol} / \mathrm{kg})$, high $\mathrm{C}_{1} / \mathrm{C}_{2}$ ratios $(449-$ 539), highly ${ }^{13} \mathrm{C}$-depleted $\mathrm{CH}_{4}(-55.0 \sim-48.4 \%$ o) and moderate $\mathrm{H}_{2}$ concentrations $(0.16-0.42 \mathrm{mmol} / \mathrm{kg})$, are very comparable to those in the Iheya North field. However, Lilly et al. (1993) suggested that most of the hydrothermal fluid $\mathrm{CH}_{4}$ in the Endeavour field would be thermogenic origin of the buried sedimentary organic matters. If the microbial methanogenesis via the sedimentary organic carbons is possible in the sediments at the ridge flank region located within several kilometers from the spreading axis, as in our MMR model, the generation and incorporation of hydrothermal fluid $\mathrm{CH}_{4}$ may be more strongly associated with the venting $\mathrm{CH}_{4}$ at the Endeavour field. Our MMR model would be not only an implication for the generation and incorporation of hydrothermal fluid $\mathrm{CH}_{4}$ in the deep-sea hydrothermal systems but also for those of cold seep $\mathrm{CH}_{4}$ (e.g., Toki et al., 2004) and for the presently uncertain hydrothermal fluid paths in the subseafloor environments (e.g., Wheat et al., 2003). In the near future, the IODP drilling will be conducted in the Iheya North hydrothermal system. It will give an excellent opportunity to testify our MMR model.

Acknowledgments-Authors are grateful to the officers, crews, and scientist group, as well as the Shinkai 2000 and Hyper Dolphin operating teams for their valuable collaboration. Authors also thank Drs. Pinti, Prol-Ledesma, and Koschinsky for their kind efforts to edit and review our manuscript. This research was supported by a Ministry of Education, Culture, Sports, Science and Technology (MEXT) Grant-in-Aid for Scientific Research (Nos. 16204045, 19253006, and 17101001), the Trans-crustal Advection and In-situ reaction of Global subseafloor Aquifer (TAIGA) project, and the Japan Society for the Promotion of Science (JSPS) Fellows (No. 18.4415). S.K. was supported by Research Fellowships for Young Scientists from JSPS (DC).

\section{REFERENCES}

Belay, N. and Daniels, L. (1988) Ethane production by Methanosarcina-Barkeri during growth in ethanol supplemented medium. Antonie Van Leeuwenhoek Journal of
Microbiology 54, 113-125.

Bischoff, J. L. and Rosenbauer, R. J. (1988) Liquid-vapor relations in the critical region of the system $\mathrm{NaCl}-\mathrm{H}_{2} \mathrm{O}$ from $380^{\circ} \mathrm{C}$ to $415^{\circ} \mathrm{C}$-a refined determination of the criticalpoint and 2-phase boundary of seawater. Geochim. Cosmochim. Acta 52, 2121-2126.

Blank, J. G., Delaney, J. R. and Des Marais, D. J. (1993) The concentration and isotopic composition of carbon in basaltic glasses from the Juan-de-Fuca Ridge, Pacific-Ocean. Geochim. Cosmochim. Acta 57, 875-887.

Butterfield, D. A., Mcduff, R. E., Mottl, M. J., Lilley, M. D., Lupton, J. E. and Massoth, G. J. (1994) Gradients in the composition of hydrothermal fluids from the endeavor segment vent field-Phase-separation and brine loss. $J$. Geophys. Res.-Solid Earth 99, 9561-9583.

Campbell, B. J., Chao, L., Sessions, A. L. and Valentine, D. L. (2009) Hydrogen isotopic fractionation in lipid biosynthesis by $\mathrm{H}_{2}$-consuming Desulfobacterium autotrophicum. Geochim. Cosmochim. Acta 73, 2744-2757.

Chiba, H., Nakashima, K., Gamo, T., Ishibashi, J., Tsunogai, U. and Sakai, H. (1993) Hydrothermal activity at the Minami-Ensei Knoll, Okinawa Trough: chemical characteristics of hydrothermal solutions. JAMSTEC J. Deep-Sea Res. 9, 271-282 (in Japanese with English abstract).

Chiodini, G., Marini, L. and Russo, M. (2001) Geochemical evidence for the existence of high-temperature hydrothermal brines at Vesuvio volcano, Italy. Geochim. Cosmochim. Acta 65, 2129-2147.

Cruse, A. M. and Seewald, J. S. (2006) Geochemistry of lowmolecular weight hydrocarbons in hydrothermal fluids from Middle Valley, northern Juan de Fuca Ridge. Geochim. Cosmochim. Acta 70, 2073-2092.

Cruse, A. M. and Seewald, J. S. (2010) Low-molecular weight hydrocarbons in vent fluids from the Mail Endeavour field, northern Juan de Fuca Ridge. Geochim. Cosmochim. Acta, doi:10.1016/j.gca.2010.1007.1013.

Delaney, J. R., Robigou, V., Mcduff, R. E. and Tivey, M. K. (1992) Geology of a vigorous hydrothermal system on the endeavor segment, Juan De Fuca Ridge. J. Geophys. Res.Solid Earth 97, 19663-19682.

Elderfield, H. and Schultz, A. (1996) Mid-ocean ridge hydrothermal fluxes and the chemical composition of the ocean. Annu. Rev. Earth Planet. Sci. 24, 191-224.

Fouquet, Y., Vonstackelberg, U., Charlou, J. L., Donval, J. P., Foucher, J. P., Erzinger, J., Herzig, P., Muhe, R., Wiedicke, M., Soakai, S. and Whitechurch, H. (1991) Hydrothermal activity in the Lau Back-Arc Basin-Sulfides and water chemistry. Geology 19, 303-306.

Gamo, T. (1995) Wide variation of chemical characteristics of submarine hydrothermal fluids due to the secondary modification processes after high temperature water-rock interaction: a review. Biogeocheimical Processes and Ocean Flux in the Western Pacific (Sakai, H. and Nozaki, Y., eds.), 425451, Terra Scientific Publishing Company (TERRAPUB), Tokyo.

Gamo, T., Sakai, H., Kim, E. S., Shitashima, K. and Ishibashi, J. (1991) High alkalinity due to sulfate reduction in the clam hydrothermal field, Okinawa Trough. Earth Planet. Sci. Lett. 107, 328-338. 
Gamo, T., Ishibashi, J., Tsunogai, U., Okamura, K. and Chiba, H. (2006) Unique geochemistry of submarine hydrothermal fluids from arc-back-arc settings of the western Pacific. Back-arc Spreading Systems: Geological, Biological, Chemical, and Physical Interactions (Christie, D. M., Fisher, C. R., Lee, S.-M. and Givens, S., eds.), 147-161, American Geophysical Union.

Gelwicks, J. T., Risatti, J. B. and Hayes, J. M. (1994) Carbonisotope effects associated with aceticlastic methanogenesis. Appl. Environ. Microbiol. 60, 467-472.

Giggenbach, W. F. (1997) Relative importance of thermodynamic and kinetic processes in governing the chemical and isotopic composition of carbon gases in high-heatflow sedimentary basins. Geochim. Cosmochim. Acta 61, 3763-3785.

Hongo, Y., Obata, H., Gamo, T., Nakaseama, M., Ishibashi, J., Konno, U., Saegusa, S., Ohkubo, S. and Tsunogai, U. (2007) Rare Earth Elements in the hydrothermal system at Okinawa Trough back-arc basin. Geochem. J. 41, 1-15.

Horibe, Y. and Craig, H. (1995) D/H fractionation in the system methane-hydrogen-water. Geochim. Cosmochim. Acta 59, 5209-5217.

Horita, J. (2001) Carbon isotope exchange in the system $\mathrm{CO}_{2}-$ $\mathrm{CH}_{4}$ at elevated temperatures. Geochim. Cosmochim. Acta 65, 1907-1919.

House, C. H., Schopf, J. W. and Stetter, K. O. (2003) Carbon isotopic fractionation by Archaeans and other thermophilic prokaryotes. Org. Geochem. 34, 345-356.

Inagaki, F., Kuypers, M. M. M., Tsunogai, U., Ishibashi, J., Nakamura, K., Treude, T., Ohkubo, S., Nakaseama, M., Gena, K., Chiba, H., Hirayama, H., Nunoura, T., Takai, K., Jorgensen, B. B., Horikoshi, K. and Boetius, A. (2006) Microbial community in a sediment-hosted $\mathrm{CO}_{2}$ lake of the southern Okinawa Trough hydrothermal system. Proc. Nat. Acad. Sci. U.S. Amer. 103, 14164-14169.

Ishibashi, J., Sano, Y., Wakita, H., Gamo, T., Tsutsumi, M. and Sakai, H. (1995) Helium and carbon geochemistry of hydrothermal fluids from the mid-Okinawa Trough back-arc basin, southwest of Japan. Chem. Geol. 123, 1-15.

Kawagucci, S., Toki, T., Ishibachi, J., Takai, K., Ito, M., Oomori, T. and Gamo, T. (2010a) Isotopic variation of molecular hydrogen in $20-375^{\circ} \mathrm{C}$ hydrothermal fluids as detected by a new analytical method. J. Geophys. Res.-Biogeosci., 115, G03021, doi:10.1029/2009JG001203.

Kawagucci, S., Shirai, K., Lan, T. F., Takahata, N., Tsunogai, U., Sano, Y. and Gamo, T. (2010b) Gas geochemical characteristics of hydrothermal plumes at the HAKUREI and JADE vent sites, the Izena Cauldron, Okinawa Trough. Geochem. J. 44, 507-518.

Kishida, K., Sohrin, Y., Okamura, K. and Ishibachi, J. (2004) Tungsten enriched in submarine hydrothermal fluids. Earth Planet. Sci. Lett. 222, 819-827.

Konno, U., Tsunogai, U., Nakagawa, F., Nakaseama, M., Ishibashi, J. I., Nunoura, T. and Nakamura, K. I. (2006) Liquid $\mathrm{CO}_{2}$ venting on the seafloor: Yonaguni knoll IV hydrothermal system, Okinawa Trough. Geophys. Res. Lett. 33, L16607, doi:16610.11029/12006gl026115.

Lilley, M. D., Butterfield, D. A., Olson, E. J., Lupton, J. E., Macko, S. A. and Mcduff, R. E. (1993) Anomalous $\mathrm{CH}_{4}$ and $\mathrm{NH}_{4}{ }^{+}$concentrations at an unsedimented mid-ocean- ridge hydrothermal system. Nature 364, 45-47.

Lupton, J., Lilley, M., Butterfield, D., Evans, L., Embley, R., Massoth, G., Christenson, B., Nakamura, K. and Schmidt, M. (2008) Venting of a separate $\mathrm{CO}_{2}$-rich gas phase from submarine arc volcanoes: Examples from the Mariana and Tonga-Kermadec arcs. J. Geophys. Res.-Solid Earth 113, B08S12, doi:10.1029/2007JB005467.

Lupton, J. E. and Craig, H. (1975) Excess He-3 in oceanic basalts-Evidence for terrestrial primordial helium. Earth Planet. Sci. Lett. 26, 133-139.

McCollom, T. M. (2008) Observation, experimental, and theoretical constraints on carbon cycling in mid-ocean ridge hydrothermal systems. Magma to Microbe: Modeling Hydrothermal Processes at Ocean Spreading Centers (Lowell, R. P., Seewald, J. S., Metaxas, A. and Perfit, M. R., eds.), 193-213, American Geophysical Union.

McCollom, T. M. and Seewald, J. S. (2007), Abiotic synthesis of organic compounds in deep-sea hydrothermal environments. Chem. Rev. 107, 382-401.

Momma, H., Iwase, R., Mitsuzawa, K., Kaiko, Y., Fujiwara, Y., Amitani, Y. and Aoki, M. (1996) Deep tow survey in Nanseisyoto region (K95-07-NSS). JAMSTEC J. Deep-Sea Res. 12, 195-210 (in Japanese with English abstract).

Moore, R. M., Punshon, S., Mahaffey, C. and Karl, D. (2009) The relationship between dissolved hydrogen and nitrogen fixation in ocean waters. Deep-Sea Res. Part I 56, 14491458.

Muramatsu, Y., Doi, T., Tomaru, H., Fehn, U., Takeuchi, R. and Matsumoto, R. (2007) Halogen concentrations in pore waters and sediments of the Nankai Trough, Japan: Implications for the origin of gas hydrates. Appl. Geochem. 22, 534556.

Nakagawa, S., Takai, K., Inagaki, F., Chiba, H., Ishibashi, J., Kataoka, S., Hirayama, H., Nunoura, T., Horikoshi, K. and Sako, Y. (2005) Variability in microbial community and venting chemistry in a sediment-hosted backarc hydrothermal system: Impacts of subseafloor phase-separation. FEMS Microbiol. Ecol. 54, 141-155.

Nakano, A., Matsumura, M. and Ishibashi, J. (2001) Geochemistry of hydrothermal fluids from the Hatoma Knoll in the South Okinawa Trough. JAMSTEC J. Deep-Sea Res. 18, 139-144 (in Japanese with English abstract).

Narita, H., Harada, K. and Tsunogai, S. (1990) Lateral transport of sediment particles in the Okinawa Trough determined by natural radionuclides. Geochem. J. 24, 207-216.

Nunoura, T., Oida, H., Nakaseama, M., Kosaka, A., Ohkubo, S., Kikuchi, T., Kazama, H., Hosoi-Tanabe, S., Nakamura, K., Kinoshita, M., Hirayama, H., Inagaki, F., Tsunogai, U., Ishibashi, J. and Takai, K. (2010) Archaeal diversity and distribution along thermal and geochemical gradients in hydrothermal sediments at the Yonaguni Knoll IV hydrothermal field in the Southern Okinawa Trough. Appl. Environ. Microbiol., 76, 1198-1211.

Obata, H., Nozaki, Y., Okamura, K., Maruo, M. and Nakayama, E. (2000) Flow-through analysis of $\mathrm{Al}$ in seawater by fluorometric detection with the use of Lumogallion. Field Anal. Chem. Technol. 4, 274-282.

Parkes, R. J., Wellsbury, P., Mather, I. D., Cobb, S. J., Cragg, B. A., Hornibrook, E. R. C. and Horsfield, B. (2007) Tem- 
perature activation of organic matter and minerals during burial has the potential to sustain the deep biosphere over geological timescales. Org. Geochem. 38, 845-852.

Pearson, A., Seewald, J. S. and Eglinton, T. I. (2005) Bacterial incorporation of relict carbon in the hydrothermal environment of Guaymas Basin. Geochim. Cosmochim. Acta 69, 5477-5486.

Penning, H., Plugge, C. M., Galand, P. E. and Conrad, R. (2005) Variation of carbon isotope fractionation in hydrogenotrophic methanogenic microbial cultures and environmental samples at different energy status. Global Change Biol. 11, 2103-2113.

Popp, B. N., Sansone, F. J., Rust, T. M. and Merritt, D. A. (1995) Determination of concentration and carbon isotopic composition of dissolved methane in sediments and nearshore waters. Anal. Chem. 67, 405-411.

Proskurowski, G., Lilley, M. D., Kelley, D. S. and Olson, E. J. (2006) Low temperature volatile production at the Lost City Hydrothermal Field, evidence from a hydrogen stable isotope geothermometer. Chem. Geol. 229, 331-343.

Romanek, C. S., Zhang, C. L. L., Li, Y. L., Horita, J., Vali, H., Cole, D. R. and Phelps, T. J. (2003) Carbon and hydrogen isotope fractionations associated with dissimilatory ironreducing bacteria. Chem. Geol. 195, 5-16.

Saegusa, S., Tsunogai, U., Nakagawa, F. and Kaneko, S. (2006) Development of a multibottle gas-tight fluid sampler WHATS II for Japanese submersibles/ROVs. Geofluids $\mathbf{6}$, 234-240.

Sakai, H., Gamo, T., Kim, E. S., Tsutsumi, M., Tanaka, T., Ishibashi, J., Wakita, H., Yamano, M. and Oomori, T. (1990a) Venting of carbon-dioxide rich fluid and hydrate formation in mid-Okinawa Trough backarc basin. Science 248, 1093-1096.

Sakai, H., Gamo, T., Kim, E. S., Shitashima, K., Yanagisawa, F., Tsutsumi, M., Ishibashi, J., Sano, Y., Wakita, H., Tanaka, T., Matsumoto, T., Naganuma, T. and Mitsuzawa, K. (1990b) Unique chemistry of the hydrothermal solution in the midOkinawa Trough backarc basin. Geophys. Res. Lett. 17, 2133-2136.

Sano, Y. and Wakita, H. (1988) Precise measurement of helium isotopes in terrestrial gases. Bull. Chem. Soc. Japan 61, 1153-1157.

Sano, Y., Tokutake, T. and Takahata, N. (2008) Accurate measurement of atmospheric helium isotopes. Anal. Sci. 24, 521525.

Schoell, M. (1980) The hydrogen and carbon isotopic composition of methane from natural gases of various origins. Geochim. Cosmochim. Acta 44, 649-661.

Schultz, A. and Elderfield, H. (1999) Controls on the physics and chemistry of seafloor hydrothermal circulation. Midocean Ridges; Dynamics of Processes Associated with Creation of New Ocean Crust (Cann, J. R., Elderfield, H. and Laughton, A., eds.), 171-209, Cambridge Univ. Press.

Seewald, J. S., Seyfried, W. E. and Shanks, W. C. (1994) Variations in the chemical and stable-isotope composition of carbon and sulfur species during organic-rich sediment alteration-an experimental and theoretical-study of hydrothermal activity at Guaymas Basin, Gulf of California. Geochim. Cosmochim. Acta 58, 5065-5082.
Shanks, W. C., III, Bohlke, J. K. and Seal, R. R., II (1995) Stable isotopes in mid-ocean ridge hydrothermal systems; interactions between fluids, minerals, and organisms. Seafloor Hydrothermal Systems; Physical, Chemical, Biological, and Geological Interactions (Humphris, S. E., Zierenberg, R. A., Mullineaux, L. S. and Thomson, R. E., eds.), 194-221, American Geophysical Union.

Sugimoto, A. and Wada, E. (1995) Hydrogen isotopic composition of bacterial methane $-\mathrm{CO}_{2} / \mathrm{H}_{2}$ reduction and acetate fermentation. Geochim. Cosmochim. Acta 59, 1329-1337.

Suzuki, R., Ishibashi, J. I., Nakaseama, M., Konno, U., Tsunogai, U., Gena, K. and Chiba, H. (2008) Diverse range of mineralization induced by phase separation of hydrothermal fluid: Case study of the Yonaguni Knoll IV hydrothermal field in the Okinawa Trough back-arc basin. Resour. Geol. 58, 267-288.

Takai, K., Nakamura, K., Toki, T., Tsunogai, U., Miyazaki, M., Miyazaki, J., Hirayama, H., Nakagawa, S., Nunoura, T. and Horikoshi, K. (2008a) Cell proliferation at $122^{\circ} \mathrm{C}$ and isotopically heavy $\mathrm{CH}_{4}$ production by a hyperthermophilic methanogen under high-pressure cultivation. Proc. Nat. Acad. Sci. U.S. Amer. 105, 10949-10954.

Takai, K., Nunoura, T., Ishibashi, J. I., Lupton, J., Suzuki, R., Hamasaki, H., Ueno, Y., Kawagucci, S., Gamo, T., Suzuki, Y., Hirayama, H. and Horikoshi, K. (2008b) Variability in the microbial communities and hydrothermal fluid chemistry at the newly discovered Mariner hydrothermal field, southern Lau Basin. J. Geophys. Res.-Biogeosci., 113, G02031, doi:02010.01029/02007jg000636.

Toki, T., Tsunogai, U., Gamo, T., Kuramoto, S. and Ashi, J. (2004) Detection of low-chloride fluids beneath a cold seep field on the Nankai accretionary wedge off Kumano, south of Japan. Earth Planet. Sci. Lett. 228, 37-47.

Toki, T., Tsunogai, U., Ishibashi, J., Utsumi, M. and Gamo, T. (2008) Methane enrichment in low-temperature hydrothermal fluids from the Suiyo Seamount in the Izu-Bonin Arc of the western Pacific Ocean. J. Geophys. Res.-Solid Earth 113, B08s13, doi:10.1029/2007jb005476.

Tsugaru, R., Tamaki, Y., Sako, M., Kimura, M. and Shimamura, K. (1991) Report on DELP 1988 cruises in the Okinawa Trough Part 4. Preliminary report on the sediment samples. Bull. Earthquake Res. Inst. Univ. Tokyo 66, 71-89.

Umezawa, T., Aoki, S., Nakazawa, T. and Morimoto, S. (2009) A high-precision measurement system for carbon and hydrogen isotopic ratios of atmospheric methane and its application to air samples collected in the western Pacific Region. J. Meteorol. Soc. Japan 87, 365-379.

Valentine, D. L., Sessions, A. L., Tyler, S. C. and Childthaisong, A. (2004a) Hydrogen isotope fractionation during $\mathrm{H}_{2} / \mathrm{CO}_{2}$ acetogenesis: hydrogen utilization efficiency and the origin of lipid-bound hydrogen. Geobiology 2, 179-188.

Valentine, D. L., Chidthaisong, A., Rice, A., Reeburgh, W. S. and Tyler, S. C. (2004b) Carbon and hydrogen isotope fractionation by moderately thermophilic methanogens. Geochim. Cosmochim. Acta 68, 1571-1590.

Vignais, P. M. (2005) H/D exchange reactions and mechanistic aspects of the hydrogenases. Coordination Chem. Rev. 249, 1677-1690.

Vogel, T. M., Oremland, R. S. and Kvenvolden, K. A. (1982) 
Low-temperature formation of hydrocarbon gases in SanFrancisco Bay sediment (California, USA). Chem. Geol. 37, 289-298.

Von Damm, K. L., Edmond, J. M., Grant, B. and Measures, C. I. (1985) Chemistry of submarine hydrothermal solutions at $21^{\circ} \mathrm{N}$, East Pacific Rise. Geochim. Cosmochim. Acta 49, 2197-2220.

Von Damm, K. L., Parker, C. M., Zierenberg, R. A., Lilley, M. D., Olson, E. J., Clague, D. A. and McClain, J. S. (2005) The Escanaba Trough, Gorda Ridge hydrothermal system: Temporal stability and subseafloor complexity. Geochim. Cosmochim. Acta 69, 4971-4984.

Welhan, J. A. and Craig, H. (1983) Methane, hydrogen and helium in hydrothermal fluids at $21^{\circ} \mathrm{N}$ on the East Pacific Rise. Hydrothermal Processes at Seafloor Spreading Centers
(Rona, P. A., Boström, K., Laubier, L. and Smith, K. L., Jr., eds.), Plenum Press, London and New York.

Wheat, C. G., Jannasch, H. W., Kastner, M., Plant, J. N. and de Carlo, E. H. (2003) Seawater transport and reaction in upper oceanic basaltic basement: chemical data from continuous monitoring of sealed boreholes in a ridge flank environment. Earth Planet. Sci. Lett. 216, 549-564.

Whiticar, M. J. (1999) Carbon and hydrogen isotope systematics of bacterial formation and oxidation of methane. Chem. Geol. 161, 291-314.

You, C. F., Butterfield, D. A., Spivack, A. J., Gieskes, J. M., Gamo, T. and Campbell, A. J. (1994) Boron and halide systematics in submarine hydrothermal systems-Effects of phase-separation and sedimentary contributions. Earth Planet. Sci. Lett. 123, 227-238. 